NIST Special Publication 1166

\title{
Energy Performance of the NIST Net Zero Energy Residential Test Facility relative to a Maryland Code-Compliant Design
}

Joshua Kneifel

http://dx.doi.org/10.6028/NIST.SP.1166
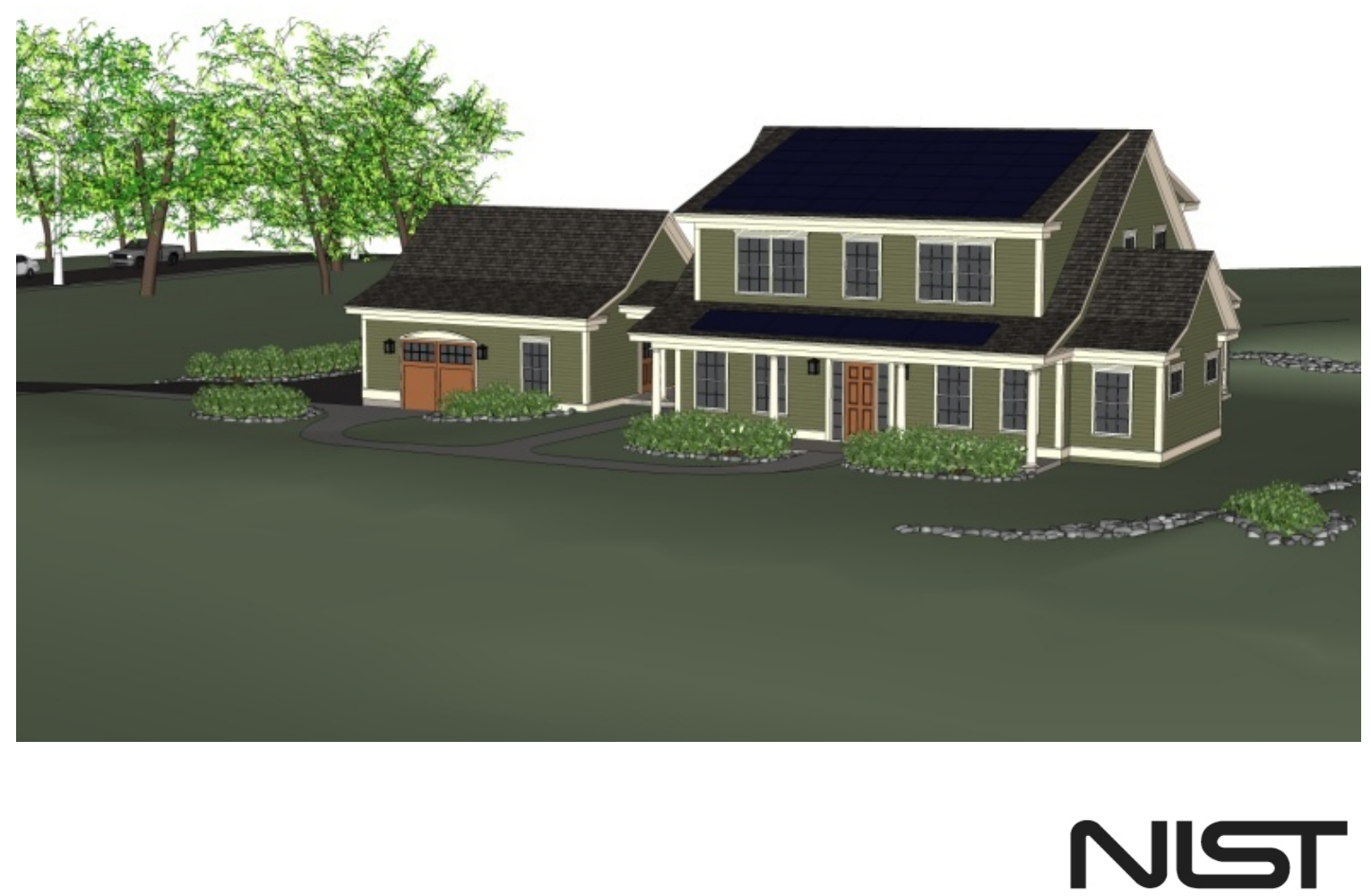

National Institute of Standards and Technology U.S. Department of Commerce 

NIST Special Publication 1166

\section{Energy Performance of the NIST Net Zero Energy Residential Test Facility relative to a Maryland Code-Compliant Design}

Joshua Kneifel

Applied Economics Office Engineering Laboratory

http://dx.doi.org/10.6028/NIST.SP.1166

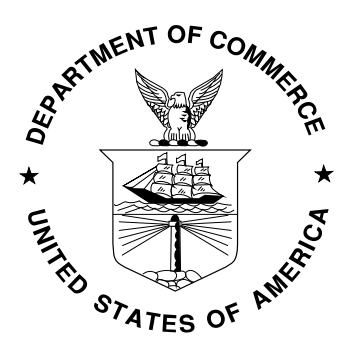

U.S. Department of Commerce Penny Pritzker, Secretary 
Certain commercial entities, equipment, or materials may be identified in this document in order to describe an experimental procedure or concept adequately. Such identification is not intended to imply recommendation or endorsement by the National Institute of Standards and Technology, nor is it intended to imply that the entities, materials, or equipment are necessarily the best available for the purpose.

National Institute of Standards and Technology Special Publication 1166

Natl. Inst. Stand. Technol. Spec. Pub. 1166, 30 pages (September 2013)

CODEN: NTNOEF

http://dx.doi.org/10.6028/NIST.SP.1166 


\begin{abstract}
The National Institute of Standards and Technology (NIST) received funding through the American Recovery and Reinvestment Act (ARRA) to construct a Net Zero Energy Residential Test Facility (NZERTF). The initial goal of the NZERTF is to demonstrate that a net-zero energy residential design can "look and feel" like a typical home in the Gaithersburg area. The demonstration phase of the project intends to demonstrate that the operation of the house does perform at "net zero," or produces as much electricity as it consumes over an entire year. The NZERTF began the demonstration phase in July 2013.

The purpose of this report is to compare the energy performance of the NZERTF design to a comparable Maryland code-compliant building design using whole building energy simulations. The analysis includes a total of eleven EnergyPlus $(E+)$ simulations, starting with the Maryland code-compliant design and then adding energy efficiency measures incrementally until all measures are included to reach the NZERTF design. This approach allows for a comparison across energy efficiency measures to determine the incremental impact for each energy efficiency measure on energy consumption.
\end{abstract}

\title{
Keywords
}

Net zero energy construction; energy efficiency; residential building; whole building energy simulation 


\section{Preface}

This study was conducted by the Applied Economics Office (AEO) in the Engineering Laboratory (EL) at the National Institute of Standards and Technology (NIST). The study is designed to document the assumptions used to create the whole building energy simulation and the resulting estimated energy performance for the demonstration phase of the Net Zero Energy Residential Test Facility (NZERTF) project. The intended audience includes researchers in the residential building sector concerned with net zero energy residential performance.

\section{Disclaimer}

Certain trade names and company products are mentioned in the text in order to adequately specify the technical procedures and equipment used. In no case does such identification imply recommendation or endorsement by the National Institute of Standards and Technology, nor does it imply that the products are necessarily the best available for the purpose.

The policy of the National Institute of Standards and Technology is to use metric units in all of its published materials. Because this report is intended for the U.S. construction industry that uses U.S. customary units, it is more practical and less confusing to include U.S. customary units as well as metric units. Measurement values in this report are therefore stated in metric units first, followed by the corresponding values in U.S. customary units within parentheses. 


\section{Acknowledgements}

The author wishes to thank everyone involved in the NZERTF project. Thank you to everyone for their advice and recommendations for the writing of this report, including Douglas Thomas and Dr. Robert Chapman of EL's Applied Economics Office, Dr. William Healy of EL's Energy and Environment Division, and Dr. Nicos S. Martys of EL’s Materials and Structural Systems Division.

\section{Author Information}

Joshua D. Kneifel

Economist

National Institute of Standards and Technology

100 Bureau Drive, Mailstop 8603

Gaithersburg, MD 20899-8603

Tel.: 301-975-6857

Email: joshua.kneifel@nist.gov 


\section{Contents}

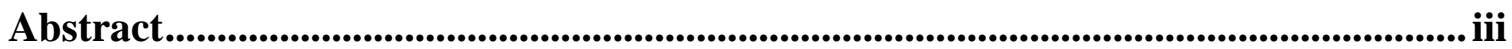

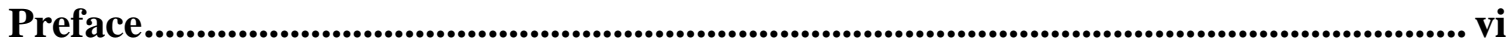

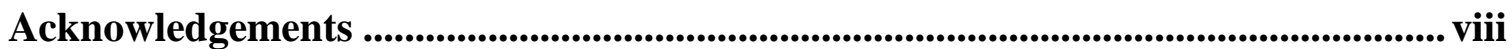

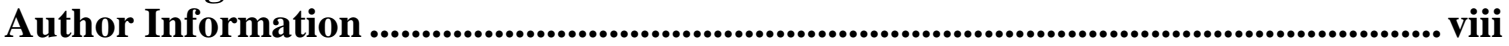

List of Acronyms ............................................................................................................ xiv

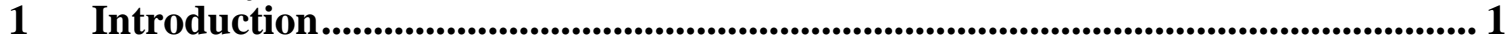

1.1 Background and Purpose.......................................................................... 1

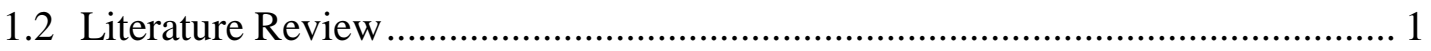

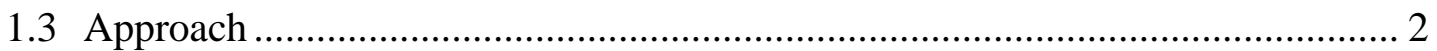

2 Assumptions................................................................................................................ 3

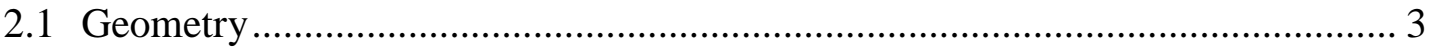

2.2 Adjustments to NZERTF Simulation................................................................ 4

3 Simulation Specifications ........................................................................................ 7

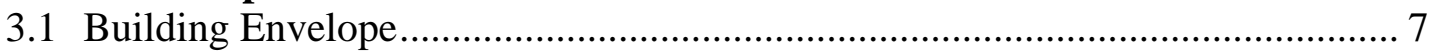

3.2 Lighting, HVAC, Domestic Hot Water, and Solar Systems .............................. 8

3.3 Incremental Simulation Specifications............................................................ 9

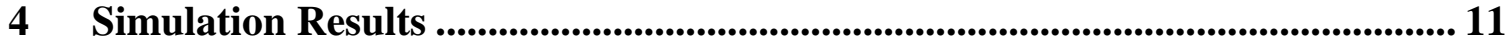

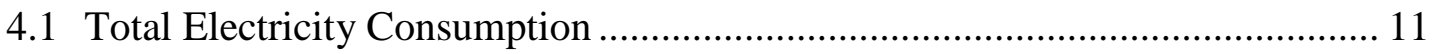

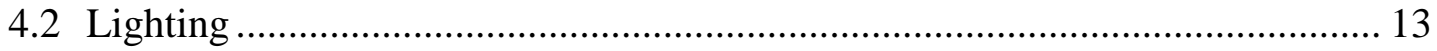

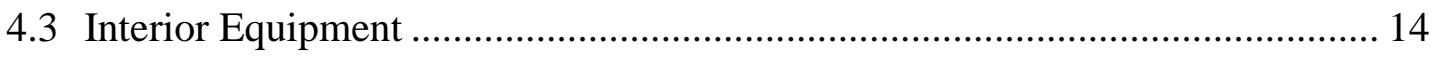

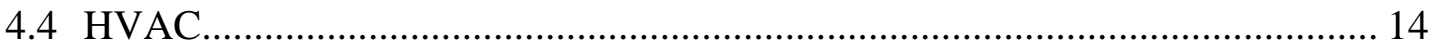

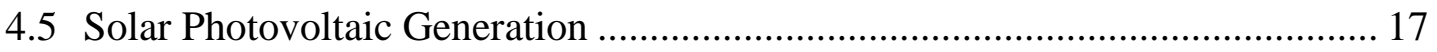

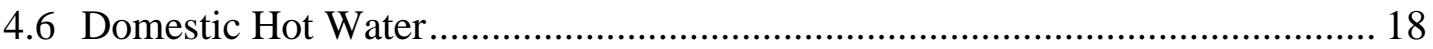

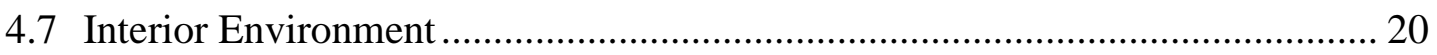

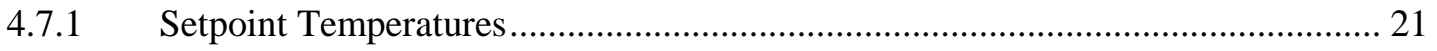

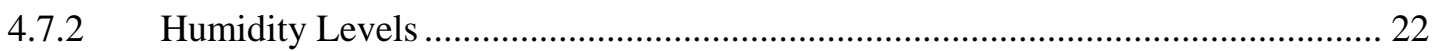

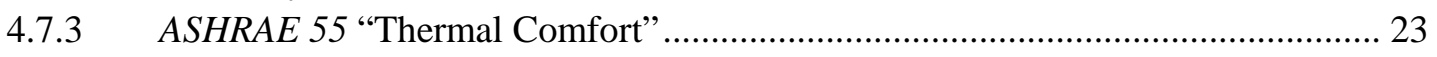

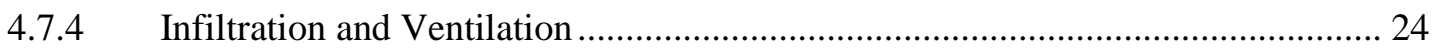

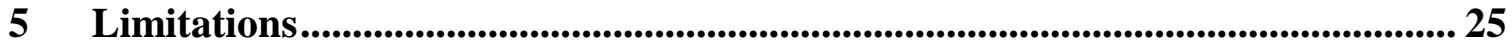

6 Discussion and Future Research.................................................................. 27

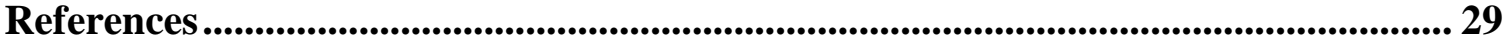




\section{List of Figures}

Figure 2-1 BSC Architectural Massing Model ............................................................ 3

Figure 2-2 Google SketchUp 3-D Representation of the E+ Model................................ 4

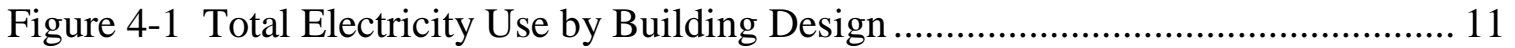

Figure 4-2 Electricity Use by Category for NZERTF and 2012 IECC - kWh and

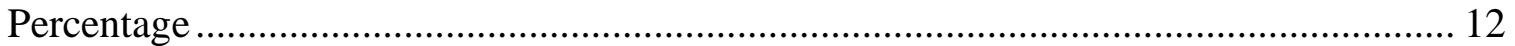

Figure 4-3 Total Electricity Use by Month for NZERTF and 2012 IECC - kWh.......... 13

Figure 4-4 Lighting Electricity Use by Room for NZERTF and 2012 IECC- kWh and

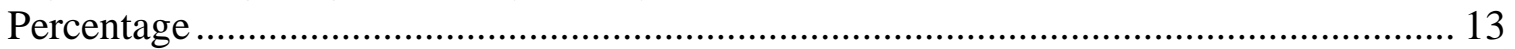

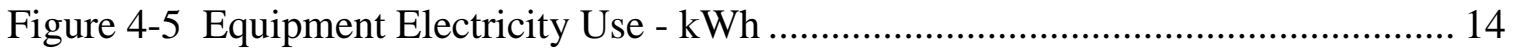

Figure 4-6 HVAC Electricity Use by Building Design - kWh ..................................... 15

Figure 4-7 HVAC Cooling and Heating Energy (kWh) for 2012 IECC and NZERTF

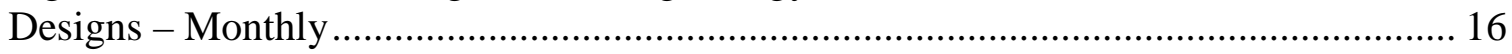

Figure 4-8 Dehumidification Performance for the NZERTF Design - Weekly ............. 17

Figure 4-9 Total Electricity Consumption and Solar PV Production (kWh) - Monthly.. 18

Figure 4-10 Total Hot Water Consumption (Percentage) - Annual............................... 19

Figure 4-11 Water Heater Electricity Use (kWh) for 2012 IECC and NZERTF - Monthly

Figure 4-12 $1^{\text {st }}$ Floor Time Setpoint Not Met While Occupied for 2012 IECC and

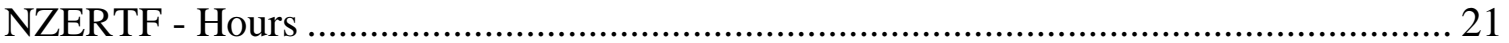

Figure 4-13 $2^{\text {nd }}$ Floor Time Setpoint Not Met While Occupied for 2012 IECC and

NZERTF - Hours.................................................................................................... 22

Figure 4-14 $1^{\text {st }}$ Floor Relative Humidity Levels for 2012 IECC and NZERTF Designs -

Hourly

Figure 4-15 Simple ASHRAE 55-2010 Not Comfortable for 2012 IECC and NZERTF

Designs - Hours.

\section{List of Tables}

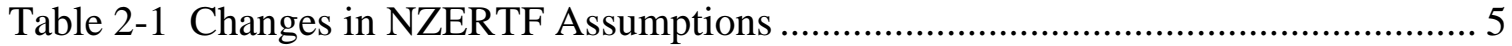

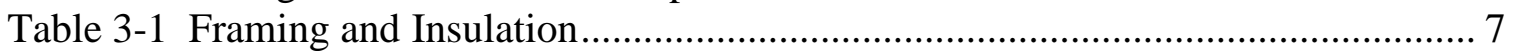

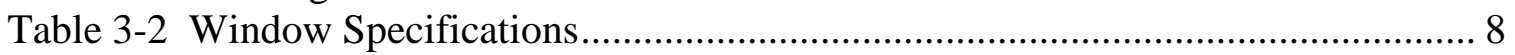

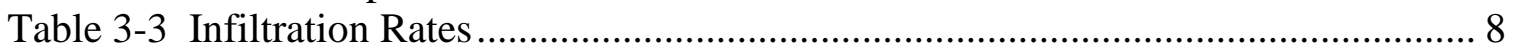

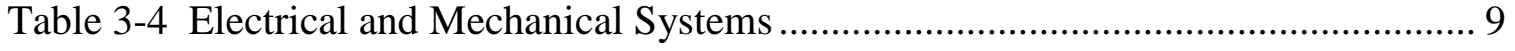

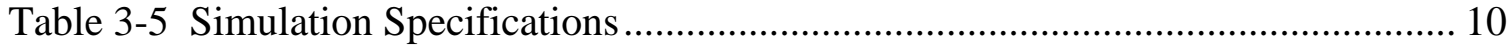

Table 4-1 Time Relative Humidity Greater than 60 \% - Hours ....................................... 22

Table 4-2 Average Outdoor Air Flow during Occupied Hours ..................................... 24 


\section{List of Acronyms}

\section{Acronym Definition}

\begin{tabular}{ll} 
AEO & Applied Economics Office \\
ARRA & American Recovery and Reinvestment Act \\
ASHRAE & American Society of Heating, Refrigerating and Air-Conditioning Engineers \\
BA & Building America \\
BSC & Building Science Corporation \\
BTP & Building Technology Program \\
CFL & compact fluorescent \\
COP & Coefficient of Performance \\
DHW & Domestic Hot Water \\
DOE & Department of Energy \\
E+ & EnergyPlus \\
EERE & Energy Efficiency and Renewable Energy \\
EL & Engineering Laboratory \\
ELA & Effective Leakage Area \\
HRV & Heat Recovery Ventilator \\
HSPF & Heating Seasonal Performance Factor \\
HVAC & Heating, Ventilating, and Air Conditioning \\
IECC & International Energy Conservation Code \\
MAT & Mean Average Temperature \\
MEL & Miscellanous Electric Load \\
NIST & National Institute of Standards and Technology \\
NREL & National Renewable Energy Laboratory \\
NZERTF & Net Zero Energy Residential Test Facility \\
OC & On Center \\
PV & Photovoltaic \\
SEER & Seasonal Energy Efficiency Ratio \\
SHGC & Solar Heat Gain Coefficient \\
TMY & Typical Meteorological Year \\
VT & Visible Transmittance \\
\hline
\end{tabular}




\section{Introduction}

\subsection{Background and Purpose}

The National Institute of Standards and Technology (NIST) received funding through the American Recovery and Reinvestment Act (ARRA) to construct a Net Zero Energy Residential Test Facility (NZERTF). The initial goal of the NZERTF is to demonstrate that a net-zero energy residential design can "look and feel” like a typical home in the Gaithersburg area. The demonstration phase of the project intends to demonstrate that the operation of the house does perform at "net zero," or produces as much electricity as it consumes over an entire year. The NZERTF began the demonstration phase in July 2013.

The purpose of this report is to compare the energy performance of the NZERTF design to a comparable Maryland code-compliant building design using whole building energy simulations. The analysis includes a total of eleven EnergyPlus $(E+)$ simulations, ${ }^{1}$ starting with the Maryland code-compliant design, which requires building to 2012 IECC, and then adding energy efficiency measures incrementally until all measures are included to reach the NZERTF design. This approach allows for a comparison across energy efficiency measures to determine the incremental impact of each energy efficiency measure on energy consumption.

\subsection{Literature Review}

The Department of Energy's (DOE) Energy Efficiency and Renewable Energy (EERE) Building Technologies Program (BTP) is responsible for funding research at the national laboratories for the Building America (BA) program. The BA program has been at the forefront of research of low-energy single-family housing design through a variety of outlets, including the BA Best Practices Series, case studies for new construction and retrofits, and technical reports and fact sheets. ${ }^{2}$ Hendron and Engebrecht (2010) defines the BA house protocols to be implemented when simulating house energy performance.

Kneifel (2012) documents the assumptions made to create a whole building energy simulation model in the $E+$ simulation software estimating the energy performance of the NZERTF. The geometry, building envelope, and hard-wired lighting design as well as some energy performance requirements are based on the specifications defined by the NZERTF project's architectural firm, Building Science Corporation (BSC). ${ }^{3}$ Based on the BSC specifications, the contractor selected interior equipment and lighting to meet those specifications. Occupant behavior assumptions for the NZERTF are defined based on Phase I operation. For some operating conditions, the model uses assumptions defined in Hendron and Engebrecht (2010). Additional documents that assist the model design are American Society of Heating,

\footnotetext{
${ }^{1}$ Department of Energy (2013)

2 Building America (2013)

${ }^{3}$ Building Science Corporation (2009)
} 
Refrigerating and Air-Conditioning Engineers (ASHRAE) 90.2-2007, ASHRAE 62.2-2010, and the ASHRAE Fundamentals Handbook.

\subsection{Approach}

This report uses the $E+$ simulation defined in Kneifel (2012) to estimate the energy performance of the NZERTF. The energy efficiency requirements defined in 2012 International Energy Conservation Code (IECC) for residential buildings are used to determine the Maryland code-compliant design. Each of the energy efficiency measures is removed from the NZERTF model, one-by-one, to reach the minimum requirements for 2012 IECC in Gaithersburg, Maryland (Climate Zone 4). 


\section{Assumptions}

The $E+$ software was chosen to design the whole building energy simulations. The simulations are run using a one-minute timestep, and the Washington-Dulles Airport Typical Meteorological Year (TMY) Version 3 weather file. The general assumptions required by $E+$ are described in detail in Kneifel (2012).

\subsection{Geometry}

The dimensions specified in BSC (2009) and shown in the architectural massing model in Figure 2-1 are used along with Google SketchUp and National Renewable Energy Laboratory's (NREL) Legacy Open Studio plug-in to construct the building geometry of the NZERTF. Total conditioned floor area of the $E+$ model is $284.6 \mathrm{~m}^{2}\left(3063 \mathrm{ft}^{2}\right)$. Actual conditioned floor area of the NZERTF is $251.7 \mathrm{~m}^{2}\left(2709 \mathrm{ft}^{2}\right)$. There are two reasons the conditioned floor area of the simulation model is $32.9 \mathrm{~m}^{2}\left(354 \mathrm{ft}^{2}\right)$ greater than the actual house design. First, the $E+$ model does not account for the open foyer/stairway, which is approximately $19.0 \mathrm{~m}^{2}\left(204 \mathrm{ft}^{2}\right)$. Second, the gable walls (west wall and east wall) of the $2^{\text {nd }}$ floor have built in storage under the gable, which decreases the conditioned floor area by approximately $14.3 \mathrm{~m}^{2}\left(154 \mathrm{ft}^{2}\right)$. These two aspects of model account for approximately $33.3 \mathrm{~m}^{2}\left(358 \mathrm{ft}^{2}\right)$, which decreases the conditioned floor area to $251.3 \mathrm{~m}^{2}\left(2705 \mathrm{ft}^{2}\right)$ or a difference of only $0.4 \mathrm{~m}^{2}\left(4 \mathrm{ft}^{2}\right)$. Even though these two aspects of the house are not considered finished floor area, they their volume of space will be conditioned.

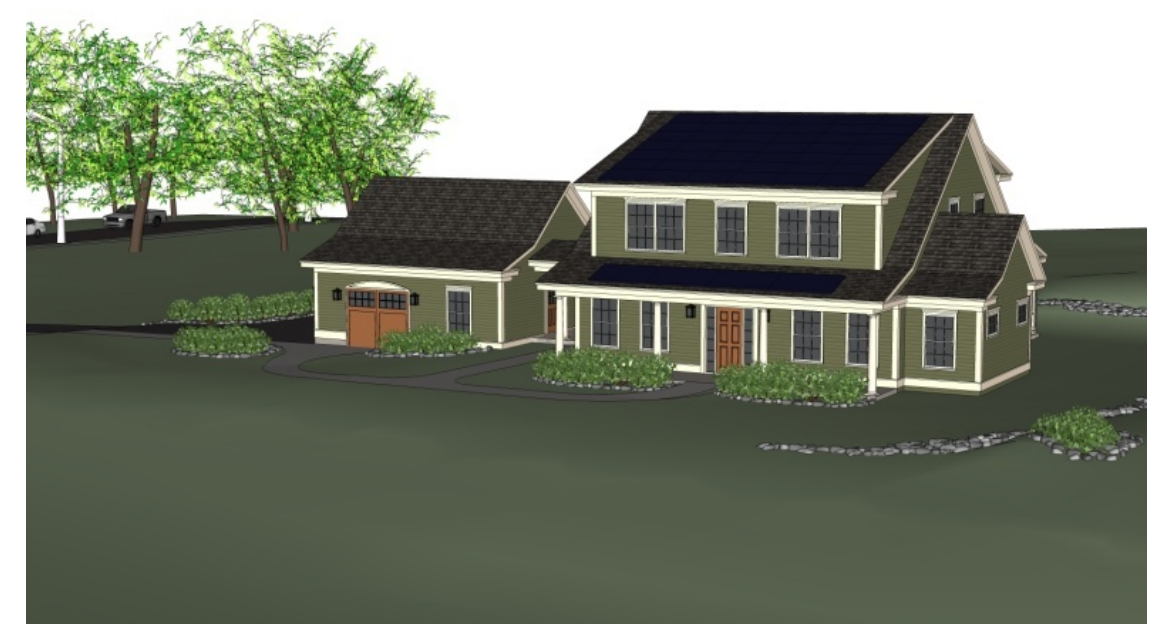

Figure 2-1 BSC Architectural Massing Model

Figure 2-2 shows the Google SketchUp three-dimensional geometry of the $E+$ model for the NZERTF. The model includes seven separate zones with two conditioned $\left(1^{\text {st }}\right.$ floor and $2^{\text {nd }}$ floor) and five unconditioned zones (open web joist space between the $1^{\text {st }}$ and $2^{\text {nd }}$ floors, basement, main attic, living room attic, and patio). The front porch and detached garage with the covered 
walkway are all treated as shading surfaces, which block sunlight but do not impact the thermal performance of the building envelope.

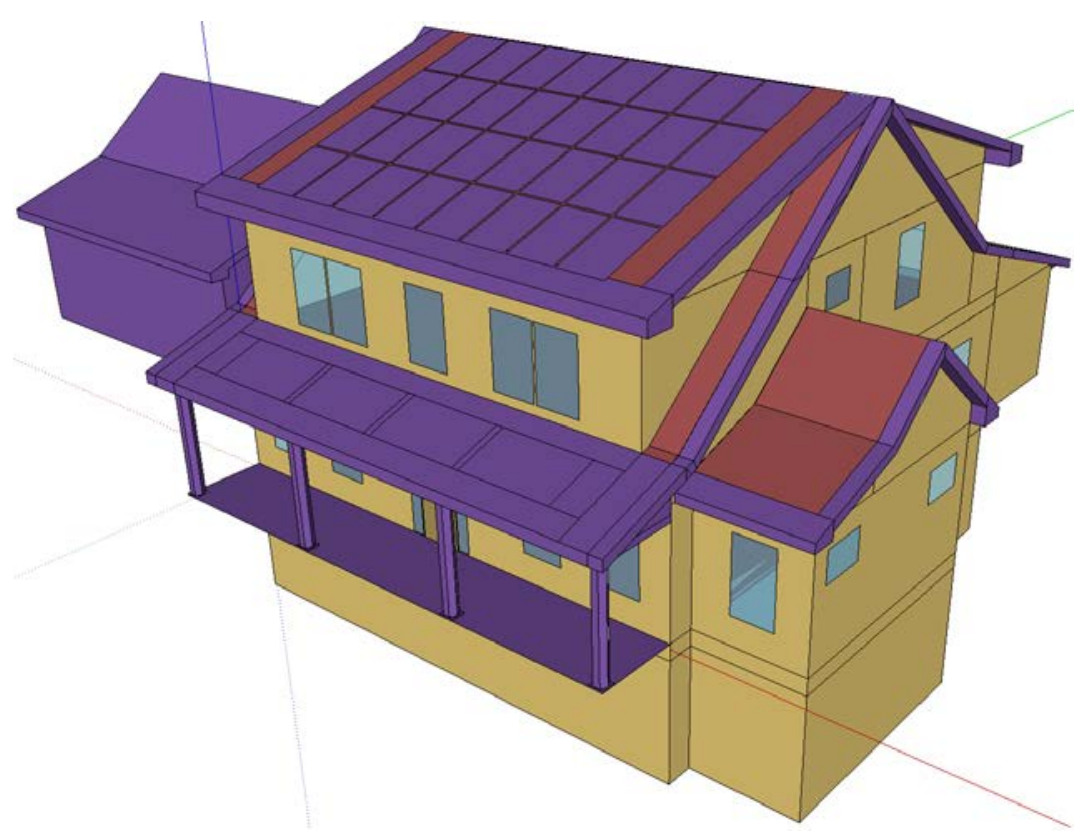

Figure 2-2 Google SketchUp 3-D Representation of the E+ Model

\subsection{Adjustments to NZERTF Simulation}

Since the publication of Kneifel (2012), there have been some adjustments to the NZERTF simulation model to better match the planned operation in the NZERTF during the demonstration phase. Each of the changes, most of which will have minor to no impact on energy performance, is listed in Table 2-1. The most significant changes are the lighting wattage adjustments, which will increase the lighting-based energy consumption. 
Table 2-1 Changes in NZERTF Assumptions

\begin{tabular}{|l|l|l|l|}
\hline Category & Subcategory & Day of Week & Detail of Change \\
\hline Occupancy & Child A in Bedroom & Saturday & Starts @ 19:30 instead of 20:30 \\
& Activity Levels & NA & Constant 65 W Sensible, 31 W Latent \\
\hline Domestic Hot Water & Kitchen Sink & Monday & Added 1 minute @ 6:05 \\
& Master Bedroom Sink & Saturday & Added 1 minute @ 8:50 \\
& Dishwasher & Friday & Changed 20:28\&21:28 from 20:15\&21:15 \\
& Clothes Washing Machine & Wednesday & Added 1 Load @ 18:30 \\
\hline Electrical Equipment & Range Hood & NA & Changed Wattage to 75 W from 330 W \\
& Iron & NA & Added to Master Bedroom \\
\hline Lighting & Kitchen & NA & Changed to 118 W from 107 W \\
& Dining Room & NA & Changed to 65 W from 13 W \\
& Living Room & NA & Changed to 118 W from 92 W \\
& Office & NA & Changed to 41 W from 28 W \\
& Master Bedroom & NA & Changed to 41 W from 13 W \\
& Bedroom 2 & NA & Changed to 41 W from 28 W \\
& Bedroom 3 & NA & Changed to 41 W from 28 W \\
& Master Bathroom & NA & Changed to 81 W from 72 W \\
& Bathroom 2 & NA & Changed to 63 W from 24 W \\
& $1^{\text {st Floor Bathroom }}$ & NA & Changed to 44 W from 46 W \\
\hline Roof Assembly & Insulation & NA & Changed to 3.81 cm (1.5 in) isocyanurate \\
& & from 2.54 cm (1.0 in) \\
\hline Thermostat & Cooling Setpoint & NA & Changed to constant 75 ${ }^{\circ} \mathrm{F}$ \\
& Heating Setpoint & NA & Changed to constant 70 $\mathrm{F}$ \\
& Availability & NA & Changed to always available \\
\hline
\end{tabular}




\section{Simulation Specifications}

There are eleven $E+$ model designs used in this report, each of which represents different combinations of energy efficiency measures between 2012 IECC and the NZERTF design. Each of the energy efficiency measures is described in detail in this chapter.

\subsection{Building Envelope}

The NZERTF design adds energy efficiency measures to each aspect of the building envelope listed in Table 3-1, Table 3-2, and Table 3-3: framing, wall, roof, fenestration, and infiltration. The NZERTF is constructed using "advanced framing," which uses 2"x6" 24" on center (OC) framing instead of the common practice of 2" $\mathrm{x} 4$ " 16 " OC framing. The thicker framing allows for greater levels of insulation within the wall cavity while decreasing the amount of wood required for framing the house, making it easier to increase the thermal performance of the building envelope.

Table 3-1 Framing and Insulation

\begin{tabular}{|l|c|c|}
\hline Insulation & NZERTF & 2012 IECC - Zone 4 \\
\hline Framing & 2"x6” 24” OC & 2"x4” 16” OC \\
Exterior Wall & R-20+24 & R-20 or R-13+5 \\
Basement Wall & R-22 & R-10 \\
Roof & R-45+30 & R-49 or R-45+4 \\
\hline Note 1: Interior + Exterior R-Value \\
Note 2: Basement Floor Insulation is the same for both \\
\hline
\end{tabular}

The 2012 IECC wall insulation requirement for Climate Zone 4 is R-20 in the wall cavity or R-13 in the wall cavity and R-5 of rigid insulation. The NZERTF design uses advanced framing and adds an additional R-24 of rigid insulation to the R-20 in the wall cavity. The basement wall requirement for 2012 IECC is R-10 of rigid insulation while the NZERTF adds R-12 to the interior of the basement wall. The 2012 IECC design with typical framing uses blown-in insulation on the attic floor to reach R-49 of continuous insulation. The 2012 IECC design with advanced framing uses R-45 blown-in insulation in the rafters with R-4 rigid insulation on the exterior of the roof. The NZERTF roof construction uses the R-45 insulation in the rafters and adds rigid insulation to the exterior roof to reach an additional R-30.

The fenestration surface construction materials for windows are defined based on three simple parameters: U-factor, Solar Heat Gain Coefficient (SHGC), and Visible Transmittance (VT). This approach allows the rated window performance to be modeled while simplifying window "materials" and "constructions" in the simulation. The window parameters can be seen in Table 
3-2, and are based on the minimum requirements specified in 2012 IECC and the BSC window specifications. ${ }^{4}$

Table 3-2 Window Specifications

\begin{tabular}{|l|l|c|c|}
\hline Field & Units & NZERTF & 2012 IECC - Zone 4 \\
\hline U-Factor & $\mathrm{W} / \mathrm{m}^{2}-\mathrm{K}$ & 1.1356 & 1.9875 \\
Solar Heat Gain Coefficient & & 0.25 & 0.35 \\
Visible Transmittance & & 0.40 & 0.40 \\
\hline
\end{tabular}

The maximum envelope air leakage rate in the 2012 IECC allowed for residential structures in Climate Zone 4 is 3 air changes per hour at $50 \mathrm{~Pa}$. The air tightness of the NZERTF was measured at 0.61 air changes per hour at $50 \mathrm{~Pa}$ using a blower door test. ${ }^{5}$ These results, shown in Table 3-3, are converted into effective leakage area (ELA) for the simulations and then split between the $1^{\text {st }}$ floor and $2^{\text {nd }}$ floor based on fraction of volume. ${ }^{6}$

\section{Table 3-3 Infiltration Rates}

\begin{tabular}{|l|c|c|}
\hline Air Leakage & NZERTF & 2012 IECC - Zone 4 \\
\hline Air Changes at $50 \mathrm{~Pa}$ & 0.61 & 3.00 \\
\hline ELA $-1^{\text {st }}$ Floor $\left(\mathrm{cm}^{2}\right)$ & 98.8 & 403.6 \\
\hline ELA $-2^{\text {nd }}$ Floor $\left(\mathrm{cm}^{2}\right)$ & 90.2 & 368.1 \\
\hline
\end{tabular}

\subsection{Lighting, HVAC, Domestic Hot Water, and Solar Systems}

Table 3-4 shows that the NZERTF design implements energy efficiency measures in the lighting, heating, ventilation, and air conditioning (HVAC), and domestic hot water (DHW) systems, and installs a solar thermal hot water system and solar photovoltaic system. The 2012 IECC requires $75 \%$ of all light fixtures to be high efficiency. The NZERTF replaces the remaining $25 \%$ of non-high efficiency light bulbs (incandescent) with high efficiency compact fluorescent (CFL) bulbs.

\footnotetext{
${ }^{4}$ These parameters assume no difference in performance of the windows regardless of the window type (awning or double hung).

${ }^{5}$ Everyday Green (2012)

${ }^{6}$ The ELA should have been split based on the fraction of surface area for each floor, not volume. However, this should not make a significant difference in the results.
} 
Table 3-4 Electrical and Mechanical Systems

\begin{tabular}{|llll|}
\hline Building System & Component & NZERTF & 2012 IECC-based System \\
\hline Lighting & Light Bulbs & 100 \% Efficient Lighting & 75 \% Efficient Lighting \\
\hline HVAC & Air Conditioning & Heat Pump (SEER 15.8) & Heat Pump (SEER 13.0) \\
& Heating & Heat Pump (HSPF 9.05) & Heat Pump (HSPF 7.7) \\
& Ventilation/Outdoor Air & Heat Recovery Ventilator & Min. Outdoor Air (0.04 ms) \\
\hline DHW & Water Heater Tank & Heat Pump Water Heater & Electric Water Heater \\
\hline Solar & Solar Thermal System & 2 Panel with 80 gallon tank & None \\
& Solar PV System & $10.2 \mathrm{~kW}$ & None \\
\hline * SEER = Seasonal Energy Efficiency Ratio & & \\
** HSPF = Heating Seasonal Performance Factor & & \\
\hline
\end{tabular}

The 2012 IECC design assumes a federal minimum efficiency heat pump with continuous outdoor air of $0.04 \mathrm{~m}^{3} / \mathrm{s}$. ${ }^{7}$ The NZERTF replaces the minimum efficiency heat pump with a high-efficiency heat pump, and adds a dedicated outdoor air system with a heat recovery ventilator (HRV). The NZERTF replaces the electric water heater with a thermal efficiency of 0.98 in the 2012 IECC design with a heat pump water heater with a coefficient of performance (COP) of 2.6 and electric back with thermal efficiency of 0.98. Additionally, the NZERTF installs two solar thermal panels and 80 gallon storage tank to preheat water entering the heat pump water heater. The NZERTF installs the largest possible solar photovoltaic (PV) system $(10.2 \mathrm{~kW})$ based on the surface areas of the roof.

\subsection{Incremental Simulation Specifications}

Table 3-5 shows the Maryland code-compliant design simulation (baseline) and the ten incremental simulations considered in this study, with each changing one component in the baseline simulation to meet the NZERTF component design. Simulation 1 replaces typical 2"x4" 16 " OC framing with "advanced framing," which uses 2"x6" 24" OC framing to decrease fraction of the wall and roof accounted for by wood framing. Simulation 2 through Simulation 4 replace the wall construction, roof construction, and windows with the NZERTF designs, respectively. Simulation 5 decreases the infiltration rate from 3 air changes per hour at $50 \mathrm{~Pa}$ in the Maryland code-compliant design to 0.61 air changes per hour at $50 \mathrm{~Pa}$, which is the rate measured by the NZERTF blower door test. Simulation 6 increases the percentage of light fixtures with high efficiency light bulbs from $75 \%$ to $100 \%$. Simulation 7 replaces the typical heat pump with a high efficiency heat pump and separate HRV system. Simulation 8 replaces the

\footnotetext{
${ }^{7}$ Low air leakage rates without including mechanical ventilation of outdoor air into the house could lead to concerns over indoor air quality. Therefore, 2012 IECC requires that any house with an air leakage rate of less than 3 air changes per hour must include mechanical ventilation that meets either the International Residential Code or International Mechanical Code. The Maryland state energy code for residential buildings requires a minimum ventilation rate that is equivalent to those defined in the ASHRAE 62.2-2010. Since the HRV system is designed to meet ASHRAE 62.2 requirements, the mechanical ventilation rate for the simulations without the HRV system is assumed to be equivalent to those rates. The heat pump fan is used to supply a constant outdoor air flow, and the associated electricity consumption is captured in the "HVAC Fan" category.
} 
electric water heater with a heat pump water heater. Simulation 9 adds a solar thermal system to the DHW system. Simulation NZERTF adds the $10.2 \mathrm{~kW}$ solar PV system to the roof of the house to complete the NZERTF design.

\section{Table 3-5 Simulation Specifications}

\begin{tabular}{|l|l|l|}
\hline Simulation & Design & Detail \\
\hline Sim. 2012 IECC & 2012 IECC - Climate Zone 4 & 2x4 16 OC; R-49 Ceiling - Floor; R-13+5 Wall \\
Sim. 1 & 2012 IECC - Climate Zone 4 & 2x6 24 OC; R-45+4 Ceiling - Roof; R-20 Wall \\
Sim. 2 & Sim. 1 + NZERTF Wall & R-20+24 Ext. Wall; R-10+12 Basement Wall \\
Sim. 3 & Sim. 2 + NZERTF Roof & R-45+30 Roof \\
Sim. 4 & Sim. 3 + NZERTF Windows & U = 0.25, SHGC = 0.25 \\
Sim. 5 & Sim. 4 + NZERTF Infiltration & Air changes per hour at 50 Pa = 0.6 \\
Sim. 6 & Sim. 5 + NZERTF Lighting & 100 \% high-efficiency; 206W LED, 387W CFL, 60W LF \\
Sim. 7 & Sim. 6 + NZERTF HVAC & Air-to-Air Heat Pump with separate HRV System \\
Sim. 8 & Sim. 7 + NZERTF Water Heater & Heat Pump Water Heater \\
Sim. 9 & Sim. 8 + Solar Thermal & 2 Solar Panels, liters 303 liter (80 gallon) storage tank \\
Sim. NZERTF & Sim. 9 + Solar PV & 10.2 kW system \\
\hline
\end{tabular}




\section{Simulation Results}

The energy efficiency measures implemented in the NZERTF design require an incremental analysis approach to determine the amount of total energy consumption reductions that result from the adoption of each measure. This chapter will analyze the results across building components and building performance metrics.

\subsection{Total Electricity Consumption}

Figure 4-1 shows that constructing to the NZERTF specification leads to a $16242 \mathrm{kWh}$ (60 \%) reduction in annual electricity use relative to constructing to meet residential 2012 IECC requirements for Climate Zone 4 (10 $742 \mathrm{kWh}$ versus $26983 \mathrm{kWh}$ ), with net electricity consumption (solar photovoltaic electricity production minus electricity consumption) of $-4731 \mathrm{kWh}$.

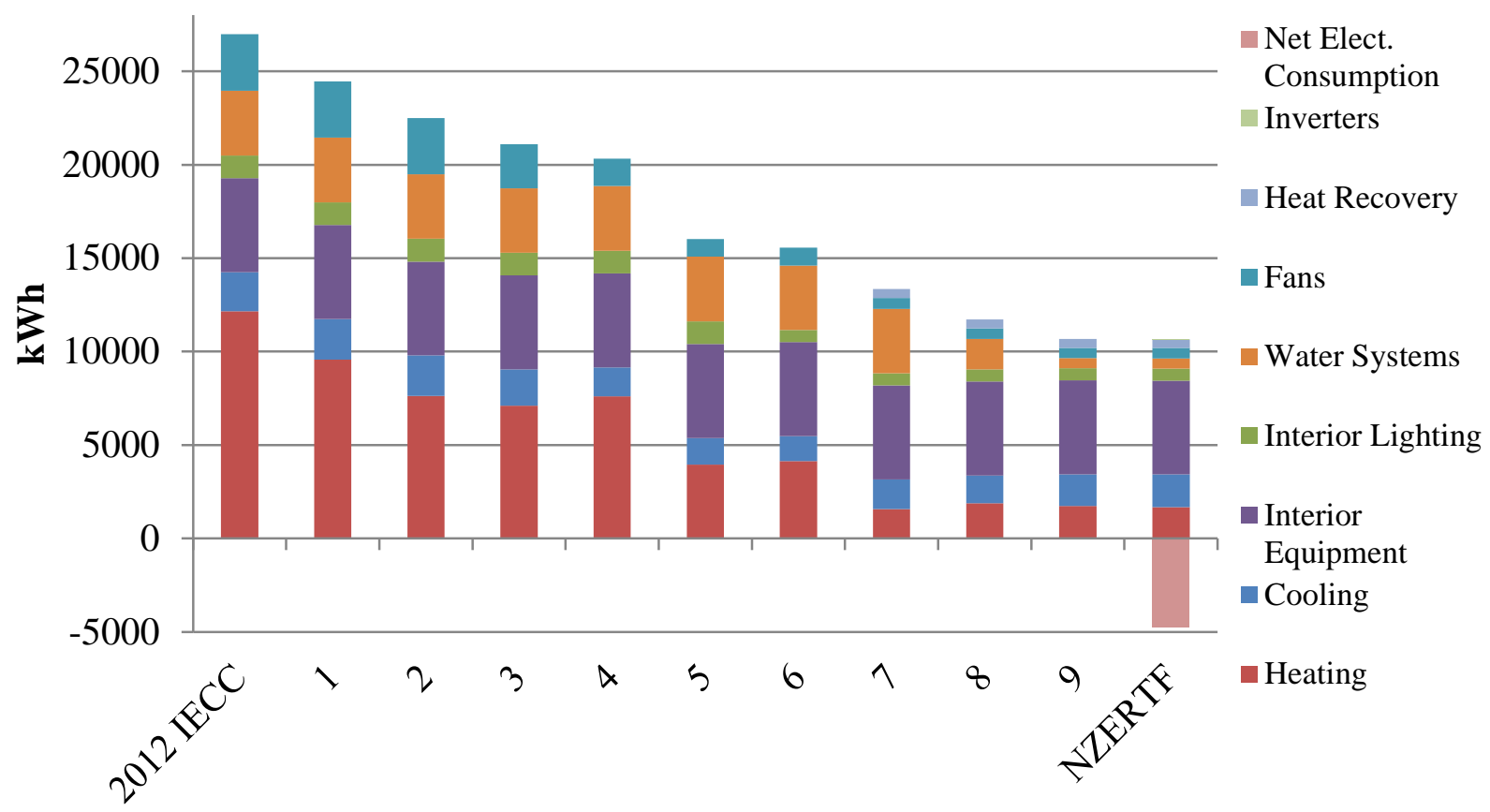

Figure 4-1 Total Electricity Use by Building Design

The most significant reductions are a result of decreasing infiltration in Simulation 5 (4292 kWh or $15.9 \%$ ), implementing advanced framing in Simulation 1 (2533 kWh or $9.4 \%)$, installing a high efficiency heat pump with dehumidification and a separate HRV system in Simulation 7 (2214 kWh or $8.2 \%$ ), increasing the R-value of the wall construction in Simulation 2 (1953 kWh or $7.2 \%$ ), and replacing an electric water heater with a heat pump water heater in Simulation 8 (1633 kWh or $6.1 \%)$. However, the order in which the energy efficiency measures are adopted in this study impact the incremental reductions realized in each simulation. For example, installing the more efficient HVAC system in Simulation 1 instead of Simulation 7 would lead to 
a larger reduction in electricity use associated with the more efficient HVAC system while decreasing the reduction associated with all the energy efficiency measures adopted in Simulation 1 through Simulation 6.

Figure 4-2 shows the breakdown of electricity use by category for the 2012 IECC and NZERTF designs, both in total $\mathrm{kWh}$ and percentage. By far, heating realizes the greatest reduction in electricity use (12 $169 \mathrm{kWh}$ to $1675 \mathrm{kWh}$ or $86 \%$ ) while the amount of cooling electricity decreases less significantly (2083 kWh to $1747 \mathrm{kWh}$ or $16 \%$ ) because it includes the consumption for the dehumidifiers. Water systems require $82 \%$ less electricity consumption (3456 kWh versus $533 \mathrm{kWh}$ ) to meet the same domestic hot water loads due to the combination of the more efficient water heater and solar thermal system. Electrical equipment is unchanged at $5025 \mathrm{kWh}$ because the 2012 IECC design includes the same appliances as the NZERTF design.
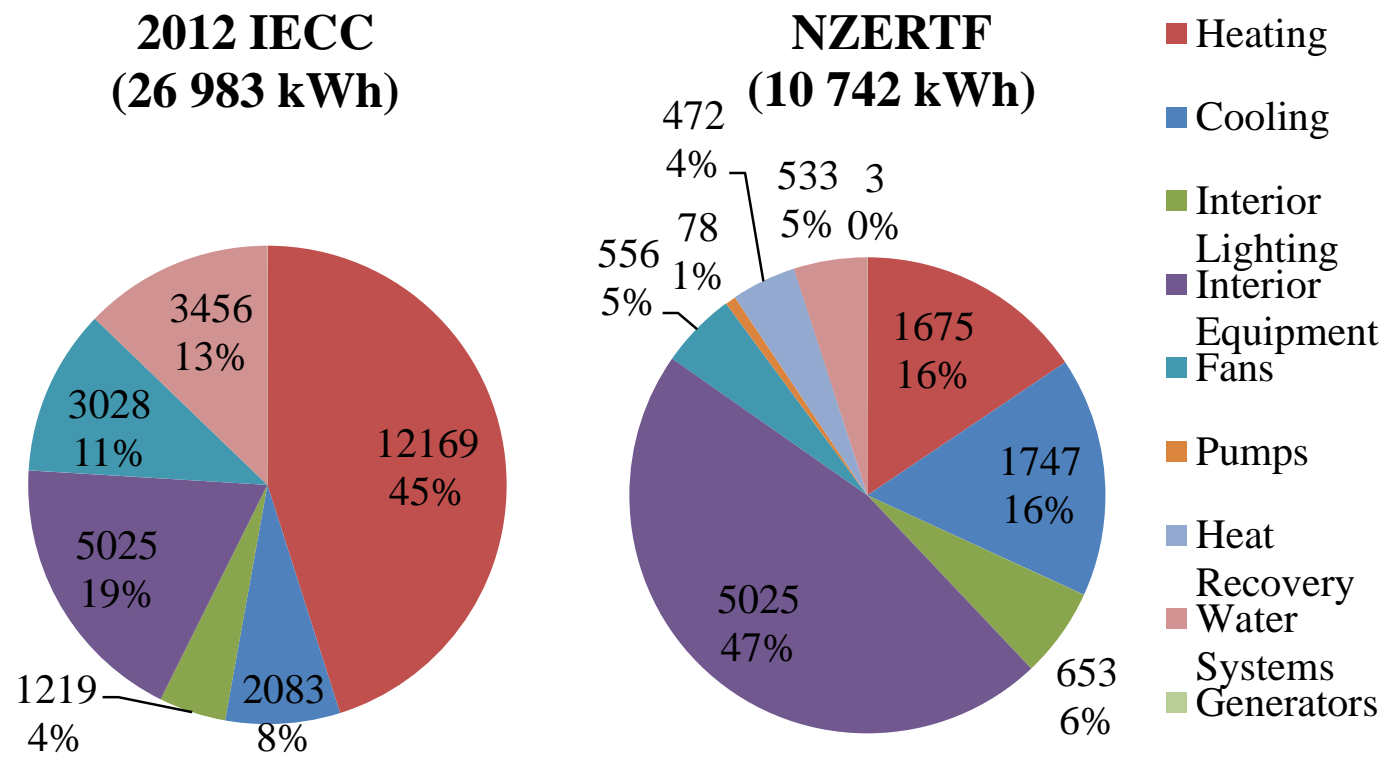

\section{Figure 4-2 Electricity Use by Category for NZERTF and 2012 IECC - kWh and Percentage}

The fraction of electricity use profile differs significantly between the 2012 IECC and NZERTF designs. The efficiency of the NZERTF results in HVAC operation (the combination of heating, cooling, fans, and heat recovery) accounting for $41 \%$ of total electricity use, which is 23 percentage points lower than the 2012 IECC design (64\%). Electrical equipment accounts for a significantly greater amount of total electricity use for the NZERTF than the 2012 IECC design because the total electricity use decreases while the electricity use for equipment remains constant at $5025 \mathrm{kWh}$.

Figure 4-3 shows the monthly electricity use profile for the NZERTF and 2012 IECC designs. The reductions in electricity use are most prevalent in the winter months due to the reduction in heating loads. 


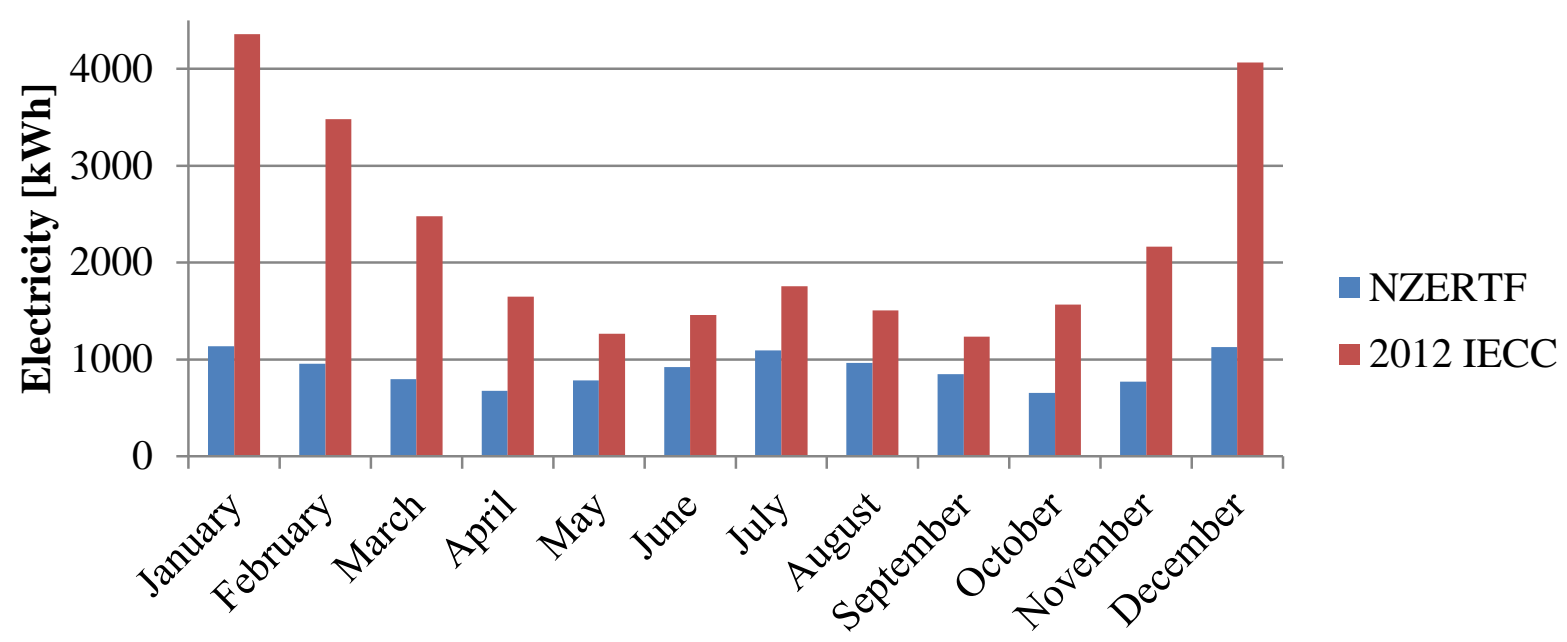

Figure 4-3 Total Electricity Use by Month for NZERTF and 2012 IECC - kWh

\subsection{Lighting}

Figure 4-4 shows how lighting varies between the NZERTF and 2012 IECC designs. Lighting is reduced for all rooms except for the kitchen because the $25 \%$ of non-high efficiency fixtures (incandescent light bulbs) in the 2012 IECC design are assumed to be replaced with CFL light bulbs. Since the kitchen uses $100 \%$ LED lighting, the room does not have any light bulbs that can be replaced. Replacing $25 \%$ of light fixtures decreases total lighting electricity consumption by $567 \mathrm{kWh}$, or $46 \%$.
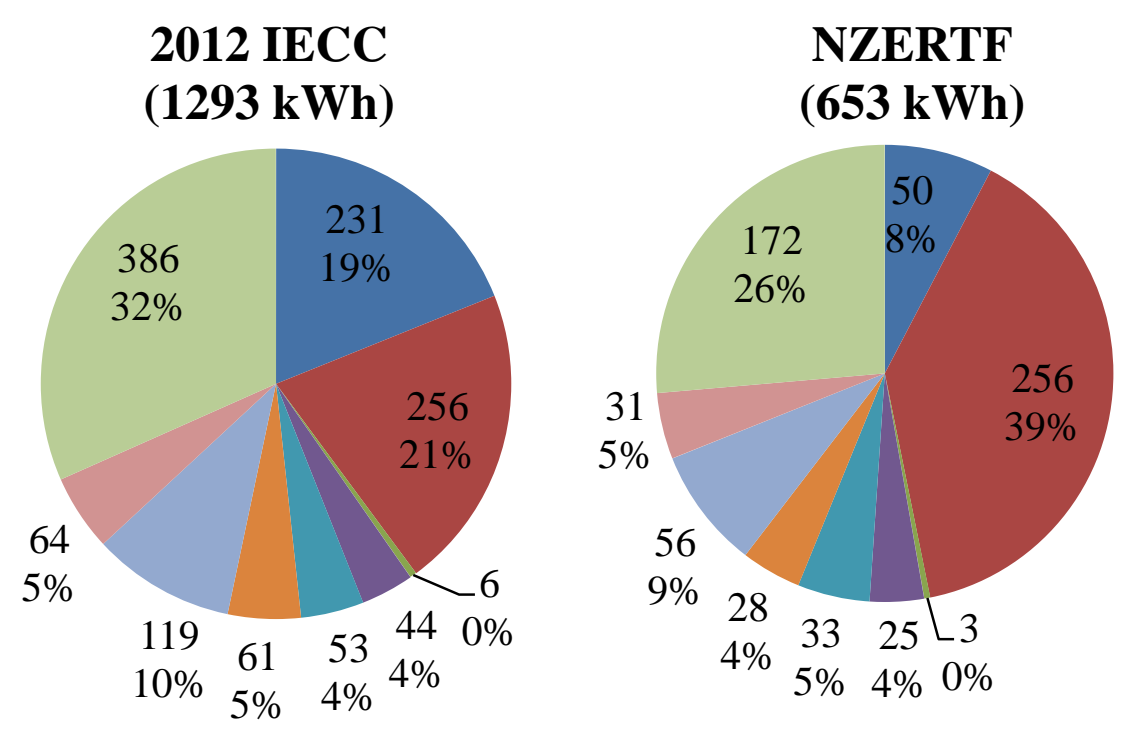

Dining Room

- Kitchen

1st Floor Bath

2nd Floor Bath

- Master Bath

- Master

Bedroom

2nd Bedroom

3rd Bedroom

Living Room

Figure 4-4 Lighting Electricity Use by Room for NZERTF and 2012 IECC- kWh and Percentage 


\subsection{Interior Equipment}

Electricity consumption for interior equipment is constant across all eleven simulations because the 2012 IECC design is assumed to use the same equipment and maintain the same occupant activity as installed in the NZERTF design. The clothes dryer consumes the most amount of electricity (1361 kWh) followed by the miscellaneous electrical loads (MELs) for the office (703 kWh), living room MELs (567 kWh), and master bedroom MELs (561 kWh).

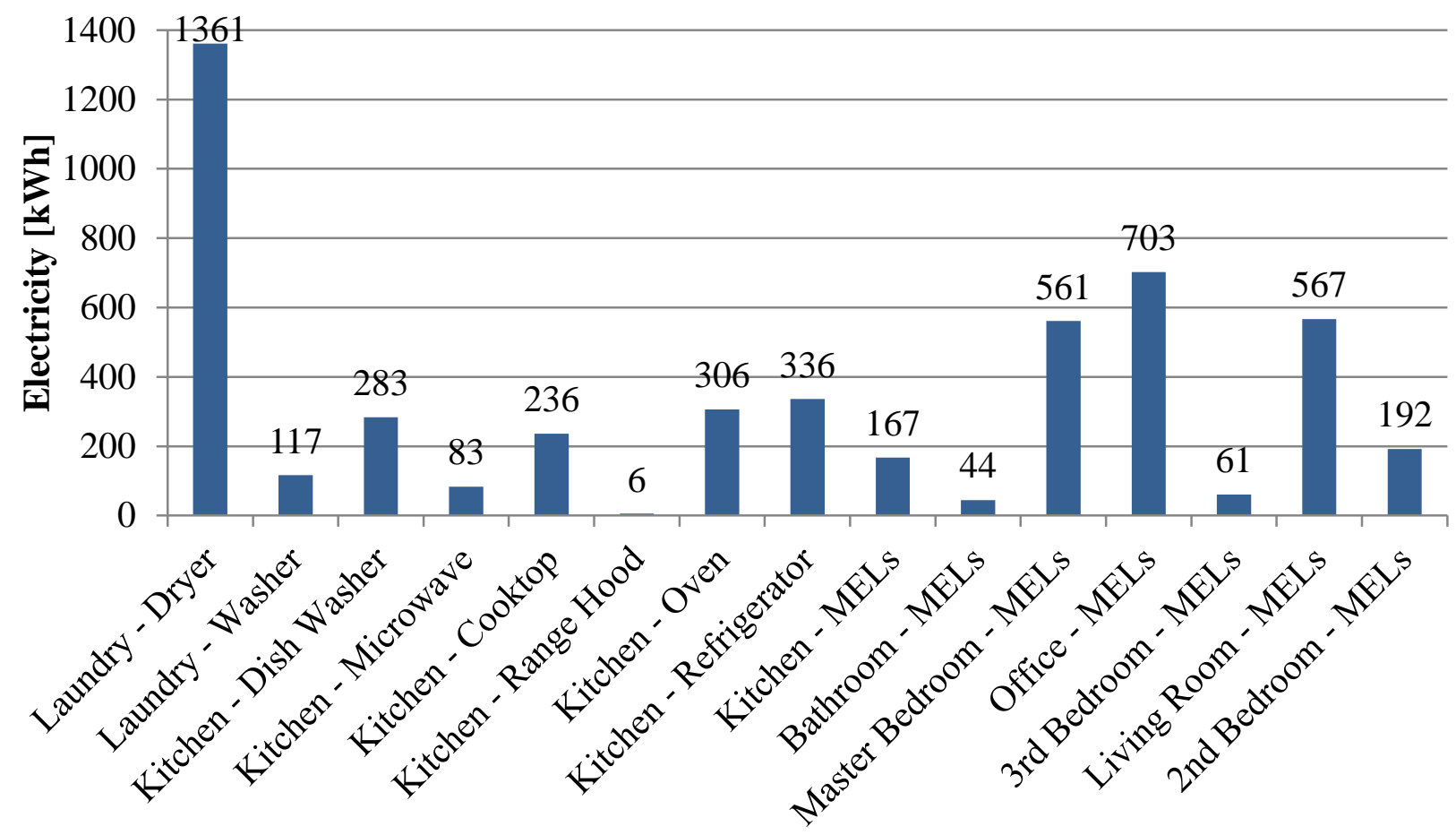

Figure 4-5 Equipment Electricity Use - kWh

\subsection{HVAC}

The electricity consumption required to meet the HVAC load for each building design is shown in Figure 4-6, and is split into 5 subcategories: heating, cooling, HVAC fans, HRV operation, and HRV fans. The heating electricity use consistently decreases from the 2012 IECC design through Simulation 5, which is a result of increases in the thermal performance of the building envelope. There is a slight increase from Simulation 5 to Simulation 6 because Simulation 6 replaces the remaining low-efficiency light fixtures with high-efficiency light fixtures, which decreases internal heat gains and increases the required heating load. There is an additional decrease in heating loads from Simulation 6 to Simulation 7 when the high-efficiency HVAC system (air-to-air heat pump with dehumidification and HRV system) replaces the minimum efficiency heat pump. The decrease in electricity consumption in heating is partially offset (10\%) by an increase in electricity consumption for cooling due to the increase in outdoor air through mechanical ventilation from constant operation of the HRV system. The HVAC 
electricity consumption is relatively constant for Simulation 7 through the NZERTF design because the remaining energy efficiency measures target the DHW system (water heater efficiency and solar thermal system) and electricity production (solar PV system). There is a slight increase from Simulation 7 to Simulation 8 because the more efficient heat pump water heater increases the heating load in the house.

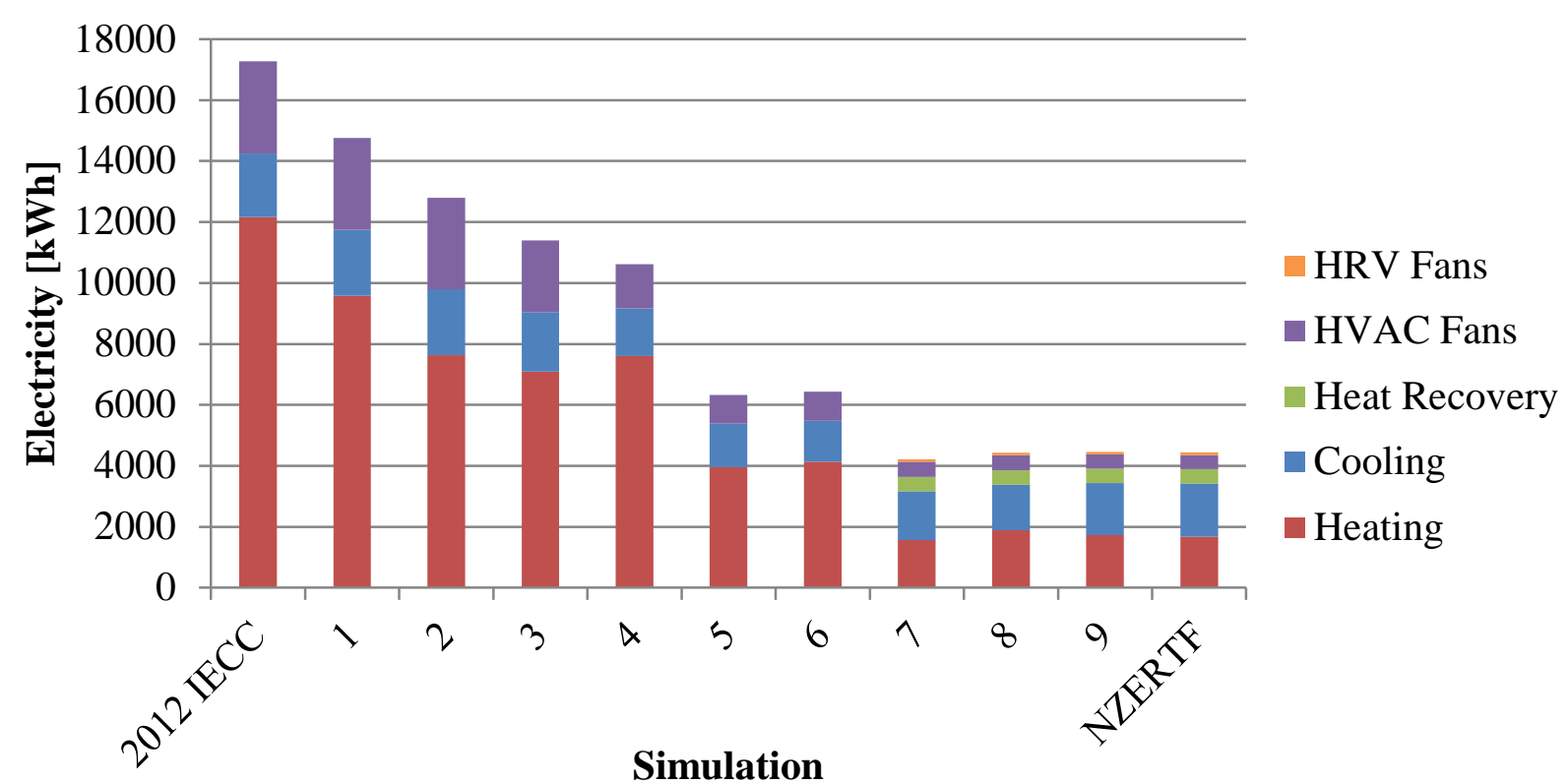

Figure 4-6 HVAC Electricity Use by Building Design - kWh

The monthly cooling and heating loads for the NZERTF and 2012 IECC simulations can be seen in Figure 4-7. Similar to the results in electricity consumption, the heating load is significantly larger than the cooling load for the 2012 IECC design while the cooling load is greater than the heating load for the NZERTF design. However, the difference is not as significant for the heating and cooling loads as for heating and cooling electricity use. Cooling loads account for $30 \%$ and $64 \%$ of total thermal loads for the 2012 IECC and NZERTF designs, respectively. Meanwhile cooling electricity consumption accounts for $15 \%$ and $51 \%$ of combined heating and cooling electricity consumption, respectively.

The reason that cooling thermal loads account for such a greater percentage than cooling electricity consumption is that the equipment is more efficient when operating in cooling mode than in heating mode. The 2012 IECC design heat pump has a nominal COP of 3.28 for cooling and COP of 2.26 for heating. Similarly, the heat pump in the NZERTF design has a COP of 3.72 for cooling and COP of 2.65 for heating. 


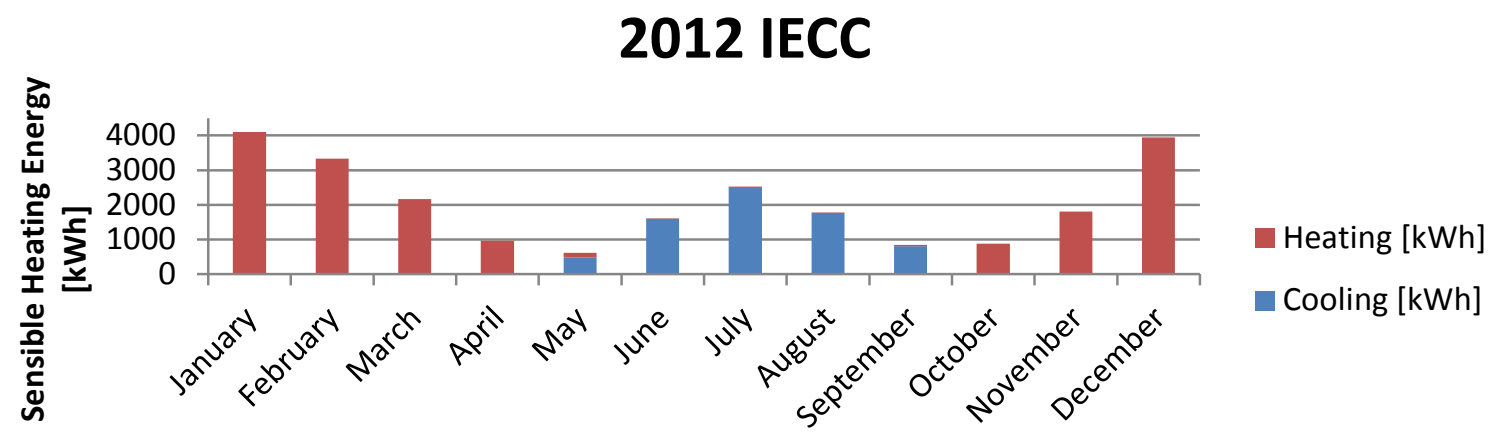

NZERTF

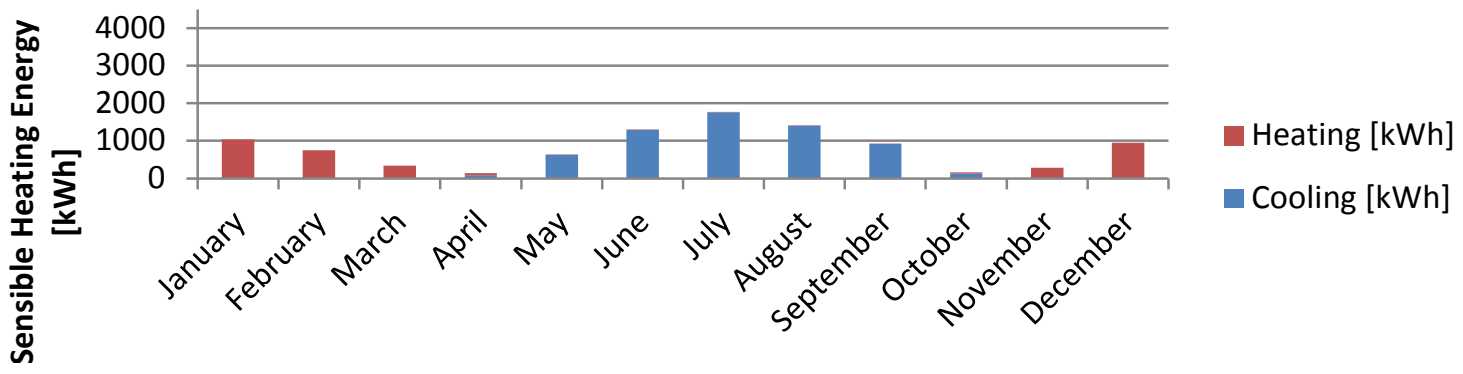

Figure 4-7 HVAC Cooling and Heating Energy (kWh) for 2012 IECC and NZERTF Designs - Monthly

Figure 4-8 shows the weekly dehumidification performance of the two zone dehumidifiers. As would be expected, most dehumidification occurs during the summer months, but there is some dehumidification that occurs in the spring and fall as well. The efficiency of the dehumidifiers is relatively constant between $0.90 \mathrm{~L}$ and $1.00 \mathrm{~L}$ of water removed from the air per kilowatt of electricity consumed, which is slightly lower than the assumed rated performance of the zone dehumidifiers. 


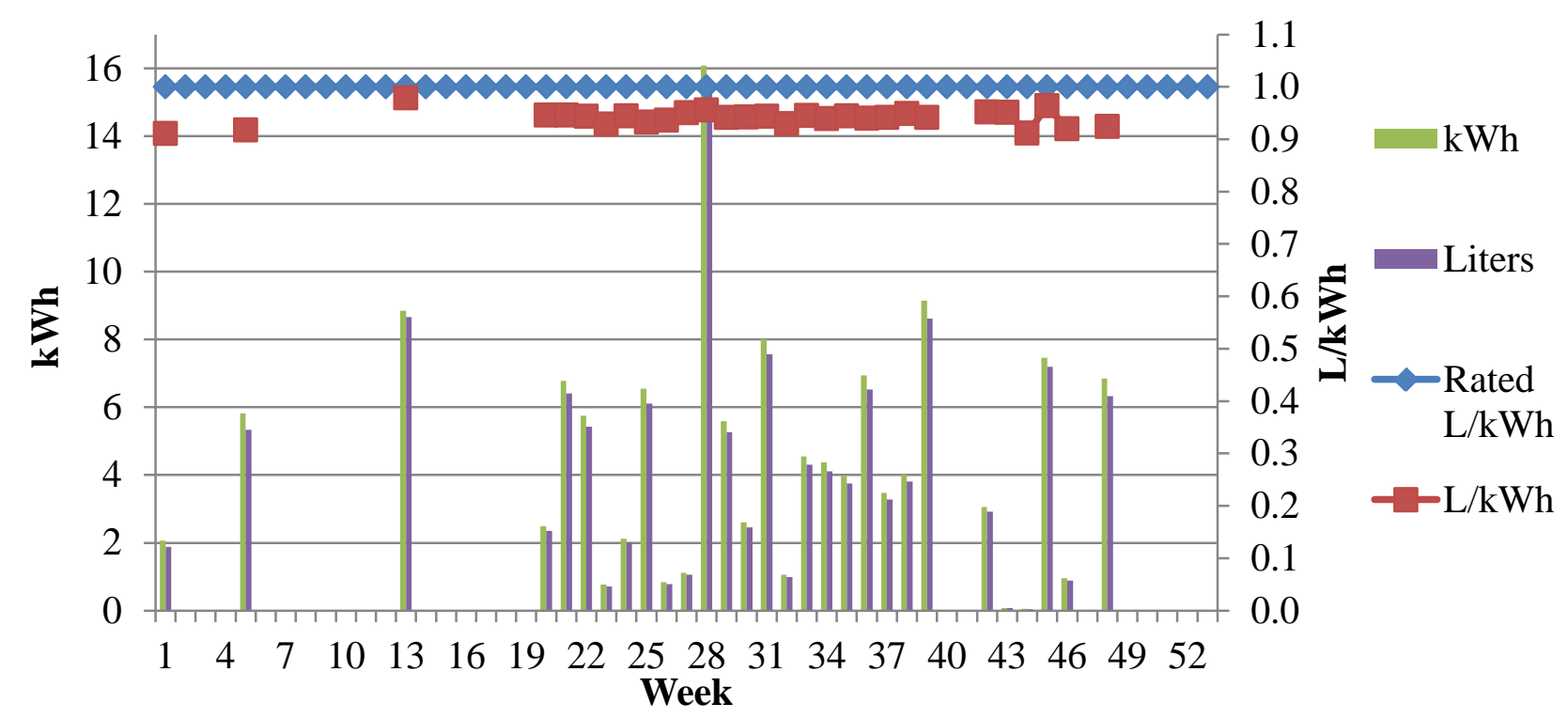

Figure 4-8 Dehumidification Performance for the NZERTF Design - Weekly

\subsection{Solar Photovoltaic Generation}

The E+ model estimates annual solar PV production of $15471 \mathrm{kWh}$, which is $144 \%$ of the house's total electricity use (10 $740 \mathrm{kWh})$. Given the assumptions used in the current simulation the NZERTF not only reaches but surpasses well beyond its net zero energy goal, as shown in Figure 4-1. ${ }^{8}$ Alternative solar PV estimates, both through different parameter values and an alternative PV software model, are used to test the sensitivity of the electricity production of the NZERTF. Two alternative $E+$ solar PV modeling approaches are used to estimate electricity production. Assuming the "simple" solar PV modeling approach with a $19.6 \%$ PV efficiency results in an estimate of $14650 \mathrm{kWh}(136 \%)$. A more conservative $18.0 \% \mathrm{PV}$ efficiency further reduces electricity production to $13500 \mathrm{kWh}(126 \%)$. Additionally, a simplified PV model (NREL's PVWATTS) was used by a NIST solar PV expert, and based on the 18.4 degree tilt of the NZERTF solar PV panels, the predicted production is $12177 \mathrm{kWh}(113 \%)$. The actual efficiency performance of the solar PV panels will make a significant difference in the energy performance of the NZERTF. However, under all four approaches the NZERTF reaches its net-zero energy goal.

Figure 4-9 shows the solar PV production for the minimum and maximum potential outcomes and consumption by the NZERTF by month. As would be expected, the summer months are when the most energy is produced while the winter months are when production lags. However, even with the varying monthly production, eight of the twelve months realize significantly greater production of electricity than is consumed by the NZERTF for the minimum performance estimate.

\footnotetext{
${ }^{8}$ This is driven by the assumed optimal solar PV performance, which can vary significantly depending on its operating conditions.
} 


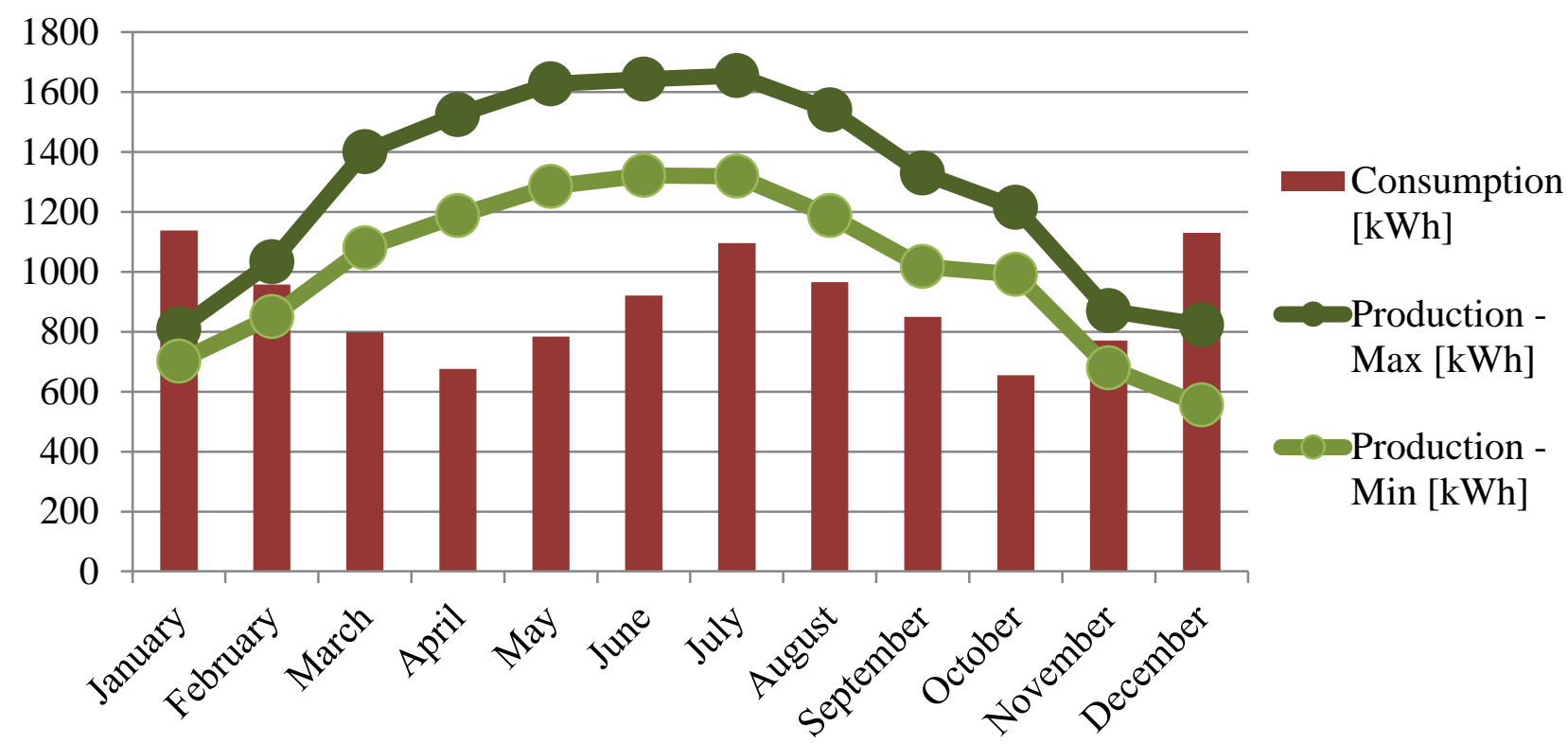

Figure 4-9 Total Electricity Consumption and Solar PV Production (kWh) - Monthly

Assuming the most conservative estimate (PVWATTS), the home owners are able to sell a net $1437 \mathrm{kWh}$ back to the electric utility ( $\$ 225$ annually at $15.69 \$ / \mathrm{kWh})^{9}$. Putting that in context, 3 of the 32 solar photovoltaic panels could be removed from the roof and the NZERTF would still consume less electricity than it produced on an annual basis. An alternative use of the excess electricity would be to power an electric car for 4224 miles. ${ }^{10}$ The 2012 IECC building design consumes $26983 \mathrm{kWh}$, which leads to an annual electricity bill of \$4234. Given the negative electricity costs of $\$ 225$ for the NZERTF design, the electricity cost savings is $\$ 4459$ annually.

The annual electricity cost savings of \$4459 for the NZERTF design increases the value of a home the owner is able to afford. The average monthly electricity cost savings is $\$ 372$.

Assuming an average 30-year fixed mortgage rate of $4.37 \%$ and a back-end debt-to-income ratio of $38 \%$, ${ }^{11}$ treating the $\$ 372 /$ month of electricity cost savings as additional income increases the owner's ability to pay by $\$ 141 /$ month or $\$ 28295$ in additional initial mortgage loan value. ${ }^{12}$ This result gives credence to the assertion that mortgage companies could consider energy performance of a house when determining the maximum mortgage value a home owner can afford.

\subsection{Domestic Hot Water}

The domestic hot water (DHW) system uses the same volume of water across all eleven simulations. Figure 4-10 shows total water use is 106970 L (28 258 gal.), or 293.1 L (77.4 gal.)

\footnotetext{
${ }^{9}$ The average price per kWh of electricity is based on data from the EIA (2011) for PEPCO during 2010.

${ }^{10}$ Assumes an electric car gets 2.94 miles per kWh (EPA, 2012).

${ }^{11}$ U.S. Weekly Average Primary Mortgage Market Survey for July 18, 2013 (Freddie Mac, 2013).

${ }^{12}$ Bankrate's Mortgage Calculator used to reverse engineer the additional mortgage loan value.
} 
per day: $53 \%$ of which is used in baths and showers, $32 \%$ in sinks, $14 \%$ by the clothes washer, and $1 \%$ for the dishwasher. Showers, baths, and sinks use a mix of hot and cold water while the washers use only hot water. The hot water use by the clothes washer would decrease if the occupants were to use cold water for a portion of their loads of laundry.

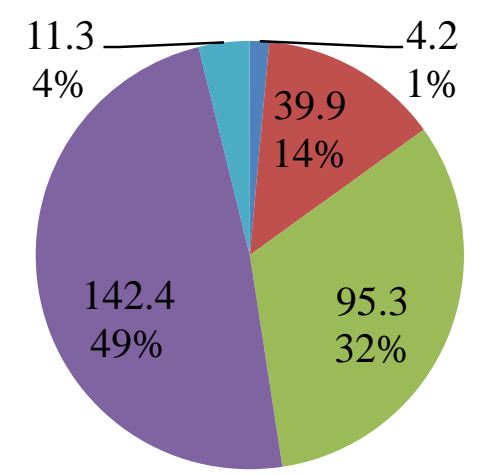

Dishwasher - 1.57 gal/cycle (1 hr)

Clothes Washer - $12.25 \mathrm{gal} /$ cycle (45 min)

Sinks - 1.5 gpm

Showers - 1.75 gpm

Baths - 1.75 gpm

\section{Figure 4-10 Total Hot Water Consumption (Percentage) - Annual}

The change in electricity consumption to meet the DHW demand is driven by the efficiency of the equipment installed. The 2012 IECC design uses an electric water heater with a thermal efficiency of 0.98, which is the least efficient type of water heater, while the NZERTF design implements a heat pump water heater with a COP of 2.6, a back-up electric resistance heater with a thermal efficiency of 0.98 , and a solar thermal system. Simulation 8 represents the incremental addition of the heat pump water heater with electric resistance back-up without preheating with the solar thermal system. The 2012 IECC design consumes $3457 \mathrm{kWh}$ to meet the DHW demand. Replacement of the electric water heater with the heat pump water heater in Simulation 8 reduces electricity use for heating water to $1623 \mathrm{kWh}$. Adding the solar thermal system further reduces electricity use to $613 \mathrm{kWh}$.

Figure 4-11 shows that electricity use to meet DHW demand varies by month for each of the three designs discussed above. For all three designs, electricity use trends down as the mean average temperature (MAT) increases and then begins to rise as the MAT decreases. The installation of the heat pump leads to a significant reduction in electricity consumption because the more efficient heat pump meets most of the heating load. However, electric resistance still accounts for $30 \%$ of electricity use to meet the DHW demand. The incorporation of the solar thermal system in the NZERTF design to preheat water entering the heat pump reduces electricity use for both the heat pump and electric resistance heating, with resistance heating only used minimally during seven months of the year and accounting for $9 \%$ of electricity used in domestic water heating. The solar thermal system requires $79 \mathrm{kWh}$ of electricity to operate, but reduces the electricity consumption of the water heater by $1010 \mathrm{kWh}$. 
2012 IECC

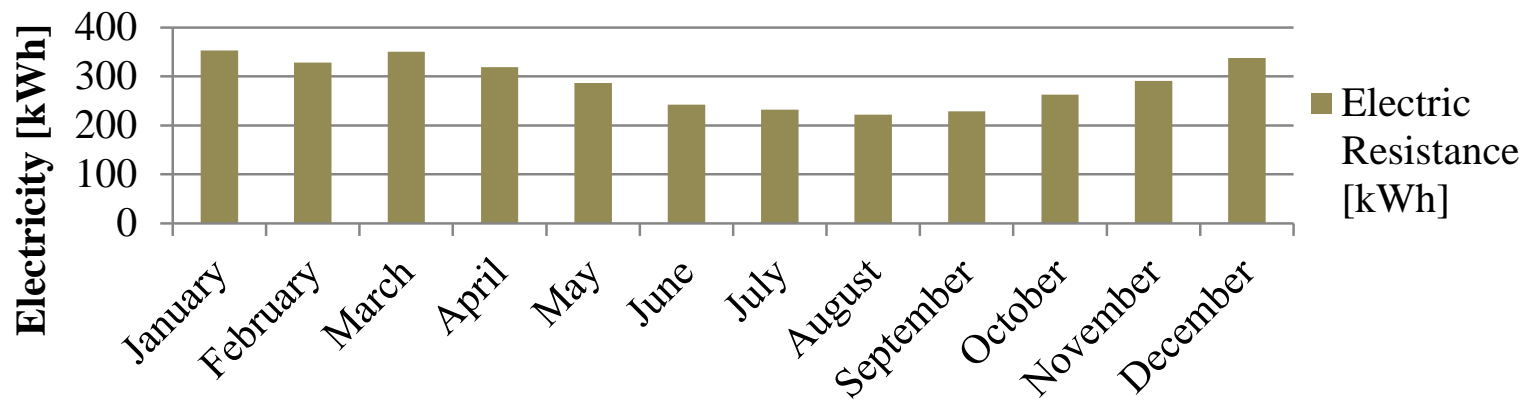

Simulation 8

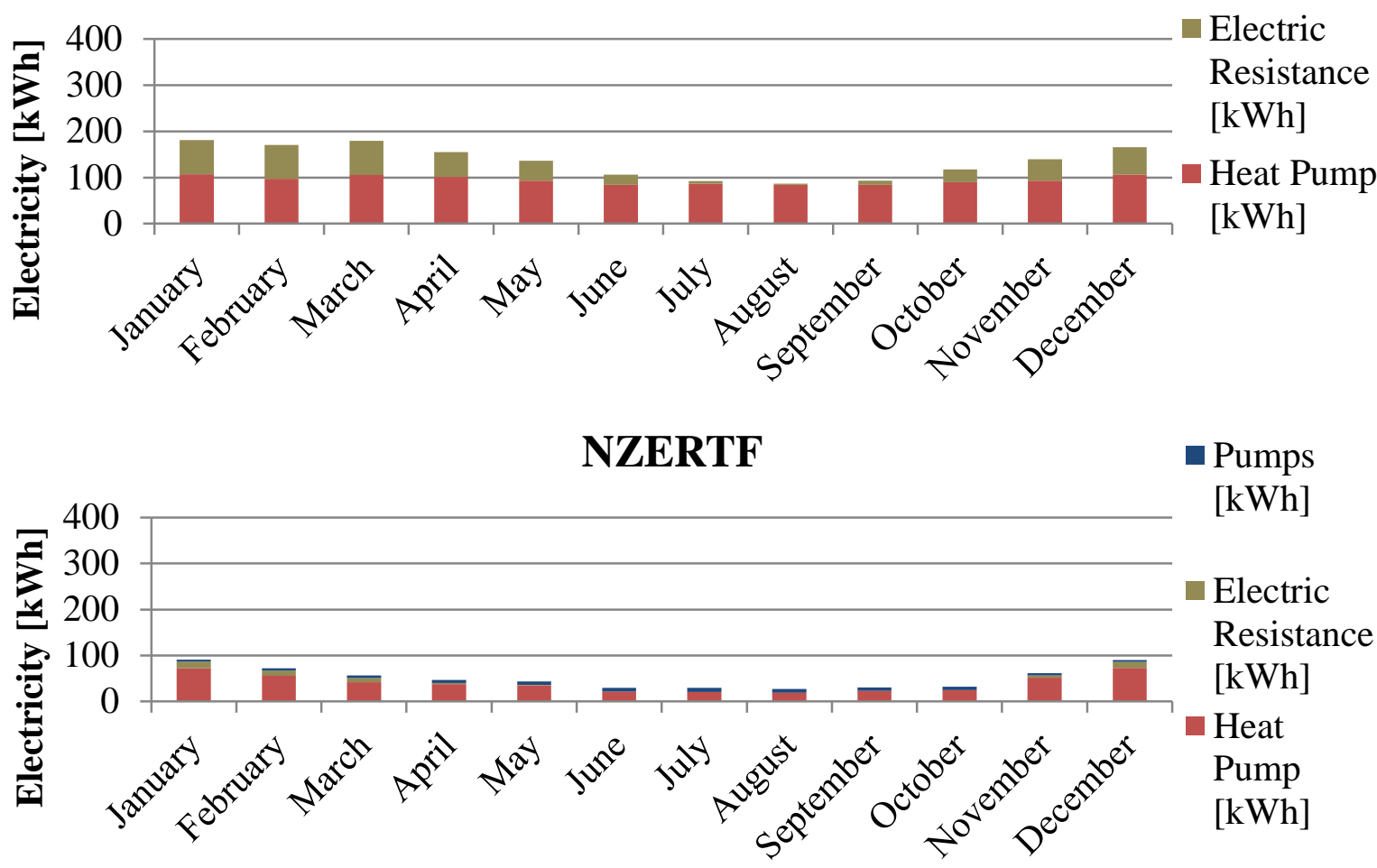

Figure 4-11 Water Heater Electricity Use (kWh) for 2012 IECC and NZERTF - Monthly

\subsection{Interior Environment}

Analysis up to this point has focused on the energy performance. However, another important aspect of building performance is the indoor environmental conditions. Given the unique characteristics of the NZERTF (high insulation, low infiltration, and mechanical ventilation control), there are concerns that the comfort levels in the house will not meet target levels. There are a number of ways in which to compare indoor environment performance using the temperature and humidity levels inside the house. 


\subsubsection{Setpoint Temperatures}

The simplest approach to determine if the house performs to the desired indoor conditions is to determine if the house is maintained at the setpoint temperatures. Figure 4-12 shows that the number of hours the setpoint temperatures are not met in the control zone ( $1^{\text {st }}$ floor) are significantly lower for the 2012 IECC design (0.03 hours) relative to the NZERTF design (8.69 hours), with cooling primarily being the setpoint that cannot be maintained. However, for both designs the total number of hours throughout the year that the setpoint is not met is quite low ( $0.001 \%$ of hours in a year or lower) because the $1^{\text {st }}$ floor is the control zone for the house.

2012 IECC

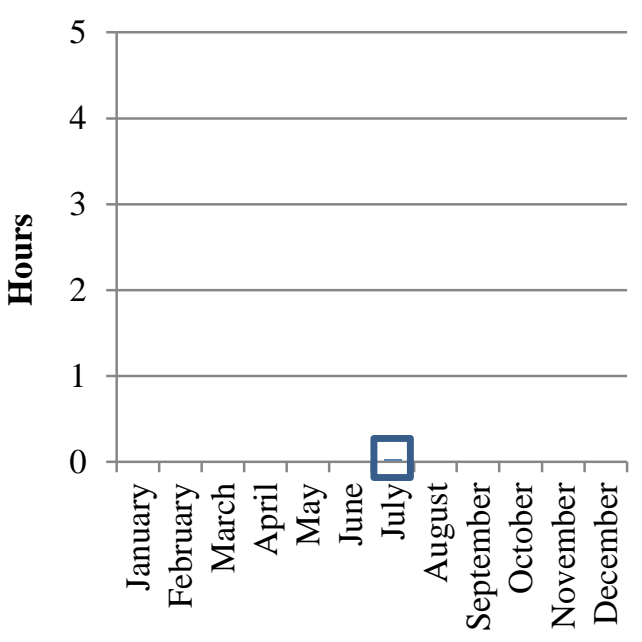

NZERTF

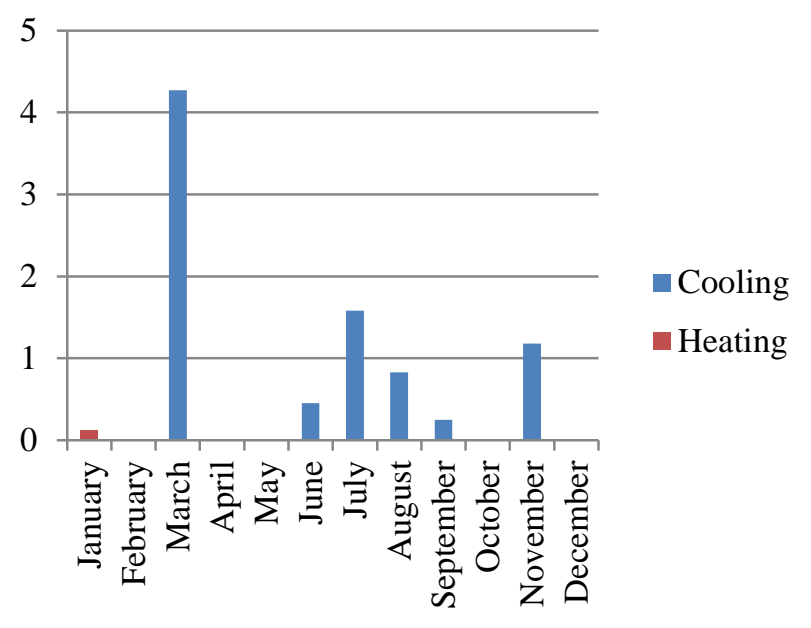

Figure 4-12 $1^{\text {st }}$ Floor Time Setpoint Not Met While Occupied for 2012 IECC and NZERTF - Hours

Figure 4-13 shows the amount of time the setpoint temperatures are not met on the $2^{\text {nd }}$ floor for the 2012 IECC and NZERTF designs, which are significantly higher than for the $1^{\text {st }}$ floor because the $2^{\text {nd }}$ floor is not the control zone. Unlike the $1^{\text {st }}$ floor, the $2^{\text {nd }}$ floor of the 2012 IECC design performance is worse than the NZERTF design, primarily because it does not meet its setpoint temperature for heating. The heating setpoint is not met for 2570 hours and the cooling setpoint not met for 623 hours. The hours that the setpoint is not met for the $2^{\text {nd }}$ floor of the NZERTF design are primarily for the cooling setpoint (947 hours) versus heating (227 hours), with most hours occurring from May through September. The NZERTF design realizes $37 \%$ fewer hours for which the setpoint temperature is not met on the $2^{\text {nd }}$ floor. Note that in the simulations, there is no air flow transferred between the $1^{\text {st }}$ floor and $2^{\text {nd }}$ floor because they are simulated as separate zones. As a result, the warmer air created by occupants and equipment on the $1^{\text {st }}$ floor does not rise to the $2^{\text {nd }}$ floor as would occur in an actual house. 

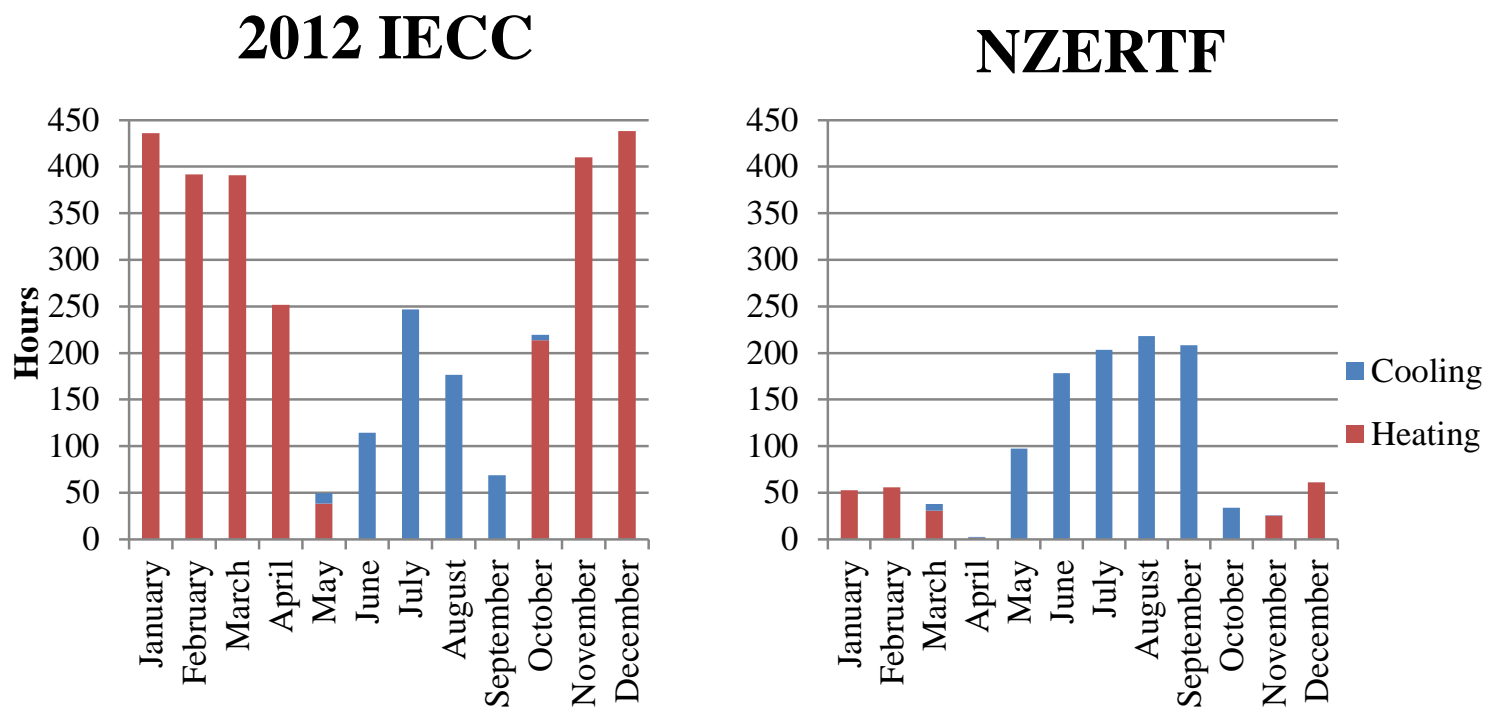

Figure 4-13 $2^{\text {nd }}$ Floor Time Setpoint Not Met While Occupied for 2012 IECC and NZERTF - Hours

\subsubsection{Humidity Levels}

Another aspect of thermal comfort is the humidity level. Table 4-1 shows that the NZERTF design leads to excellent humidity level control, with the $1^{\text {st }}$ floor and $2^{\text {nd }}$ floor realizing relative humidity levels greater than $60 \%$ for a total of three hours and 1 hour for the year, respectively. The relative humidity levels fluctuate more significantly for the 2012 IECC design, with the $1^{\text {st }}$ floor and $2^{\text {nd }}$ floor realizing humidity levels greater than $60 \%$ for $15 \%$ (1318 hours) and $16 \%$ (1415 hours) of all hours during the year, respectively.

Table 4-1 Time Relative Humidity Greater than 60 \% - Hours

\begin{tabular}{|l|rr|}
\hline \multicolumn{1}{|c|}{ Hours } & 1st Floor & 2nd Floor \\
\hline 2012 IECC & 1318 & 1415 \\
\hline NZERTF & 3 & 1 \\
\hline
\end{tabular}

Figure 4-14 shows that for some hours during the year, the humidity levels exceed $80 \%$ on the $1^{\text {st }}$ floor for the 2012 IECC design. Given these results, it may be appropriate to assume that the heat pump will be operated in cooling mode when the humidity levels are significantly over $60 \%$, which would significantly increase the electricity use for cooling. The NZERTF simulation maintains the humidity level because it includes a dehumidifier on each floor, which is used to represent dehumidification mode capability of the heat pump because it cannot currently be simulated in $E+$. Note that in the actual NZERTF, it is unlikely that the heat pump could perform as precisely as the dehumidifiers and would lead to additional hours for which the humidity level exceeds the $60 \%$ target level. 


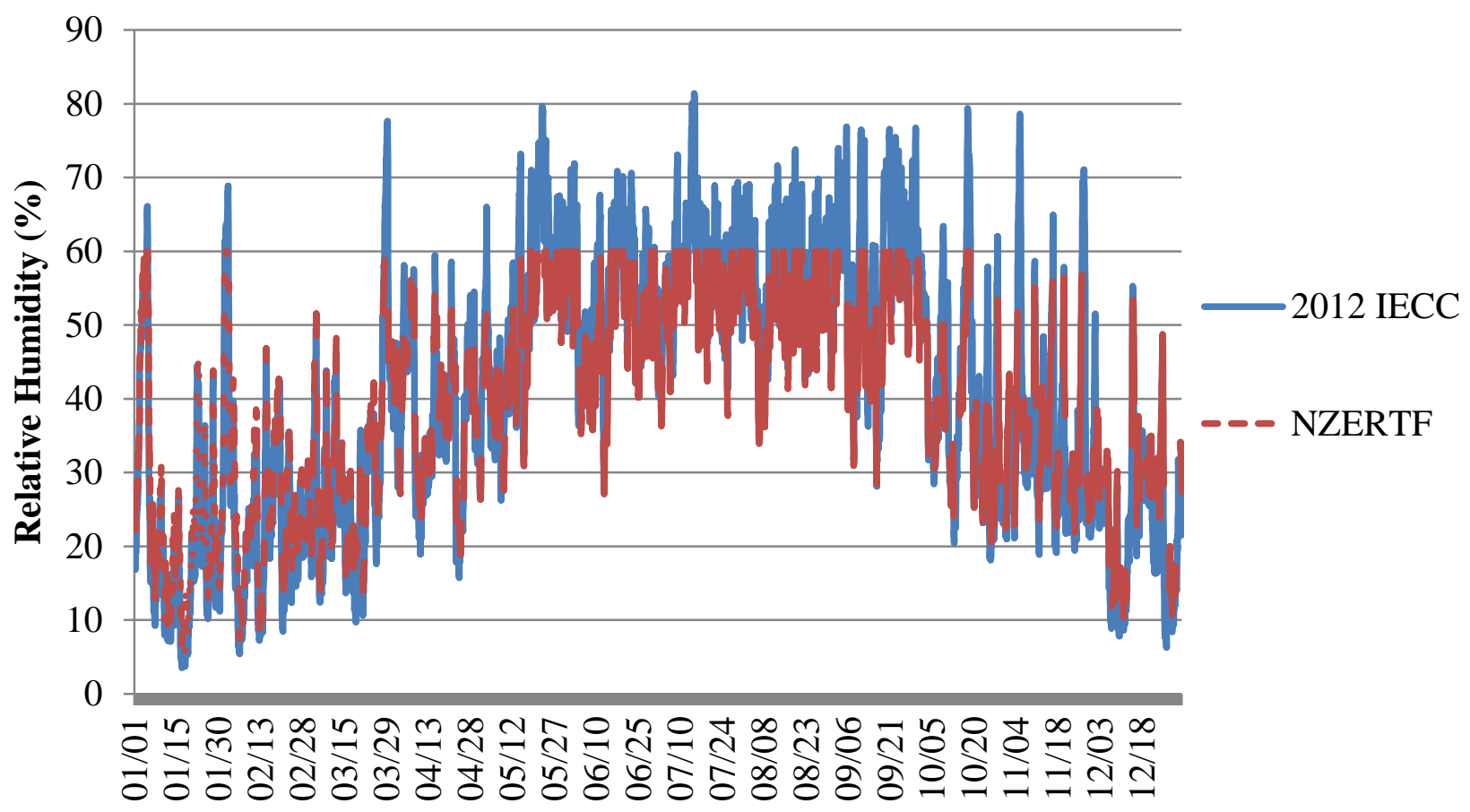

Date

\section{Figure 4-14 $1^{\text {st }}$ Floor Relative Humidity Levels for 2012 IECC and NZERTF Designs - Hourly}

\subsubsection{ASHRAE 55 “Thermal Comfort”}

The goal of temperature and humidity control is to maintain the indoor environment at acceptable thermal conditions for an inhabitant. ASHRAE Standard 55-2010 defines an approach to estimate a range of conditions (temperature and relative humidity) under which an occupant is “comfortable.” Figure 4-15 shows the number of hours for which the conditions are considered "not comfortable" according to ASHRAE 55 by month for the 2012 IECC and NZERTF design. ${ }^{13}$ For both designs, the winter months lead to more "uncomfortable" conditions, and the $2^{\text {nd }}$ floor realizes a greater number of hours in "uncomfortable" conditions. The NZERTF design has significantly fewer hours for which the thermal comfort is not maintained relative to the 2012 IECC design.

\footnotetext{
${ }^{13}$ These results are outputs from the $E+$ model for the simple approach of calculating acceptable indoor environment levels, which are based on combinations of operative temperature and humidity ratio. The calculations allow maximum flexibility in the insulation value of clothes worn by the occupant, which estimates the insulation value of summer clothes and winter clothes to be $0.078 \mathrm{~m}^{2} \mathrm{~K} / \mathrm{W}$ (0.5 Clo) and $0.155 \mathrm{~m}^{2} \mathrm{~K} / \mathrm{W}$ (1.0 Clo), respectively. For additional details, see the E+ documentation and ASHRAE 55-2010.
} 
2012 IECC

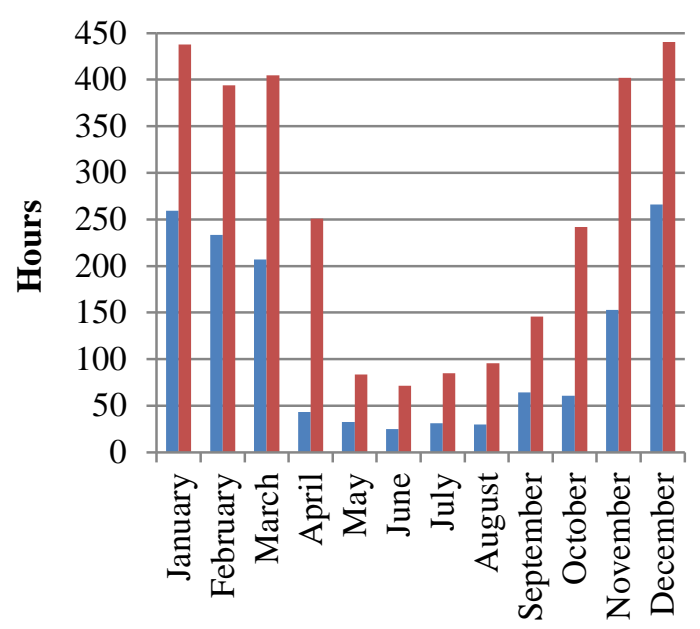

NZERTF

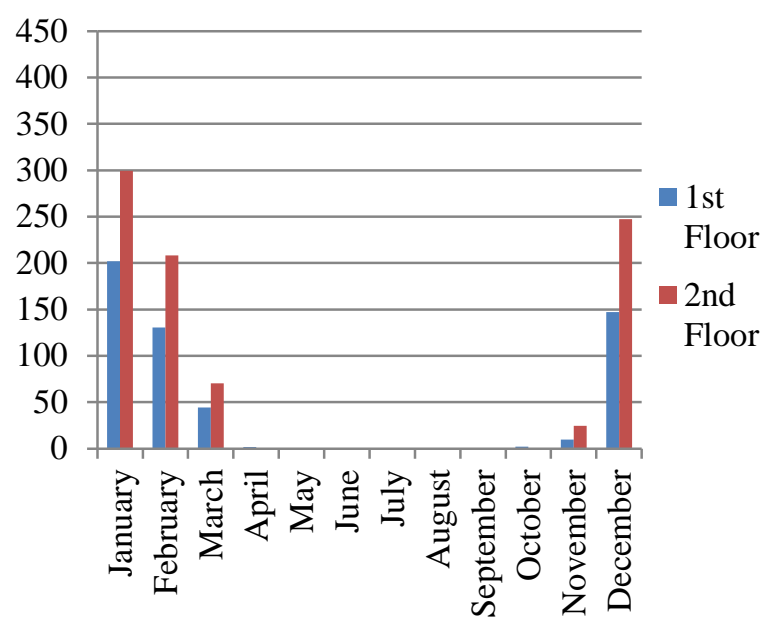

Figure 4-15 Simple ASHRAE 55-2010 Not Comfortable for 2012 IECC and NZERTF Designs - Hours

\subsubsection{Infiltration and Ventilation}

Table 4-2 shows the average air changes per hour $\left(\mathrm{h}^{-1}\right)$ from infiltration ${ }^{14}$ and mechanical ventilation calculated by E+ throughout the year for the 2012 IECC design, Simulation 5, and NZERTF design. The average outdoor air change rate is higher for the 2012 IECC design (around $0.4 \mathrm{~h}^{-1}$ ) relative to Simulation 5 and the NZERTF design (around $0.2 \mathrm{~h}^{-1}$ ) because the mechanical ventilation rate target is the same for all three designs, but the infiltration rate is reduced in Simulation 5 to meet the NZERTF air leakage rate.

Table 4-2 Average Outdoor Air Flow during Occupied Hours

\begin{tabular}{|ll|rrr|}
\hline \multicolumn{2}{|c|}{ Air Change Rate $\mathbf{( h}^{\mathbf{- 1}}$ ) } & Ventilation & Infiltration & Total \\
\hline 2012 IECC & 1st Floor & 0.13 & 0.22 & 0.35 \\
& 2nd Floor & 0.15 & 0.23 & 0.37 \\
\hline \multirow{2}{*}{ Simulation 5 } & 1st Floor & 0.13 & 0.05 & 0.19 \\
& 2nd Floor & 0.14 & 0.06 & 0.20 \\
\hline NZERTF & 1st Floor & 0.13 & 0.05 & 0.18 \\
& 2nd Floor & 0.14 & 0.06 & 0.20 \\
\hline
\end{tabular}

\footnotetext{
${ }^{14}$ Air change rates for infiltration are calculated based on the effective leakage area infiltration formula based on Sherman and Grimsrud (1980), which is a function of outdoor air temperature, indoor air temperature, ELA at 4 Pa, stack coefficient, and wind coefficient.
} 


\section{Limitations}

Whole building energy simulation software is limited in its abilities to estimate real world energy performance because it is difficult to control for all potential variables that can impact the thermal conditions in a building. There are a number of reasons that the estimated performance from the $E+$ model may vary from actual performance of a building design. A few are discussed below.

Discrepancies between the $E+$ model and the actual NZERTF design are the most prominent reasons for variations in energy performance. First, the $E+$ model does not include the stairway/foyer opening, which restricts thermal transfer between the floors and increases the conditioned floor area relative to the actual NZERTF design. The greater conditioned floor area will impact the thermal load needed to meet the thermostat set points as well as the minimum ventilation rates required for the HVAC equipment.

Second, electrical equipment consumption may be overestimated or underestimated dependent on whether equipment operates as expected. For example, it is unclear at what wattage level the clothes dryer operates throughout its cycle, or how long the cycle may last due to the "smart" technology allowing the dryer to stop once it senses the clothes are dry.

Third, air infiltration may not be accurately estimated in the $E+$ model. The infiltration rate due to building envelope leakage in the $E+$ model is simplified to an ELA based on the most recent air leakage test. The model does not account for any additional infiltration induced by occupant activities, which will underestimate the total infiltration that will occur during the demonstration phase of the NZERTF project.

Fourth, building components may not perform at the manufacturer specifications. Solar PV production may vary drastically by weather and operating conditions. The simulation assumes optimal electricity production based on the TMY3 weather file. A single year may vary enough from the historical average to either increase or decrease solar PV performance. The solar PV system may be less productive than the specifications claim for some or all weather conditions, which would result in less electricity production than is estimated by the $E+$ model. There is minimal information available for the energy performance of the HVAC and DHW systems, which could perform significantly better or worse than the simulation and drastically impact the NZERTF's energy performance. Interior equipment and lighting may also differ from the expected performance.

Fifth, the monitoring and control of the NZERTF systems may change due to unforeseen circumstances. Monitoring and controlling every aspect of the NZERTF will be a complex and difficult task. Related problems could result in significant variations in electricity use depending on if systems are used more or less often than intended. 
These limitations will be addressed whenever possible to improve the accuracy of the $E+$ simulation results. Updates based on the changes to the simulations and the related impacts on the results will be made as they occur. 


\section{Discussion and Future Research}

The estimated performance of the NZERTF design relative to the 2012 IECC design leads to several interesting results. First, the NZERTF leads to a reduction of $60 \%$ in energy consumption relative to the 2012 IECC design while doing a better job at controlling the indoor environment in terms of temperature and relative humidity. If the NZERTF were to be compared to an older IECC edition, the percentage reduction would be even more significant, especially since the goal for 2012 IECC was to be $30 \%$ more efficient than 2006 IECC.

Second, the greatest reduction in electricity consumption is realized from reducing unwanted infiltration (16\%), implementing advanced framing (9\%), installing a high efficiency HVAC system (8\%), increasing the R-value of wall construction (7\%), and installing a heat pump water heater (6\%). However, the order in which the energy efficiency measures are adopted in this study may impact the incremental reductions realized in each simulation.

Third, the electrical equipment (appliances and miscellaneous plug loads) become more important as a house becomes more efficient because the electrical equipment has the same performance across all simulations while electricity use in the other categories decreases. In order to further decrease electricity use in the NZERTF, it will require more efficient appliances and lower miscellaneous plug loads through more efficient electronics (e.g., TVs) and changes to occupant behavior in plug load use (e.g. unplugging laptop chargers when not in use) to further reduce electricity consumption.

This study does not consider the resulting energy efficiency performance of each combination of the ten energy efficiency measures. A more in depth study should be done to determine how the order in which energy efficiency measures are adopted impact the incremental increase in energy efficiency for each measure. This comprehensive set of $E+$ models covering all potential combinations of energy efficiency measure adoption can be used in collaboration with life-cycle costing and life-cycle assessment approaches to analyze the incremental benefits and costs of building to reach net-zero annual energy consumption. The resulting sustainability performance analysis will assist in determining the optimal combination of energy efficiency measures for a low-energy house design given current economic conditions.

Given all the assumptions required to generate an $E+$ model, the use of sensitivity analysis to test the importance of these assumptions will assist in better understanding the aspects of the NZERTF. Sensitivity analysis can be used to look at a number of building characteristics (e.g. air tightness and orientation), occupant behavior (e.g. setpoint temperatures and DHW demand), and mechanical equipment performance (e.g. HVAC and water heater efficiency). The sensitivity of the energy performance for factors outside of the building can also be tested, such as shading from surrounding trees or buildings or extreme weather. The $E+$ model can also be altered to determine how additional energy efficiency measures would impact the energy performance of the NZERTF, including equipment that is already installed in the NZERTF. For example, each of 
the three geothermal heat pump systems could be included in the analysis to determine the impacts of systems on the NZERTF's energy performance. Natural ventilation could be introduced by opening and closing windows based on the outdoor temperature to account for common human behavior. 


\section{References}

ANSI/ASHRAE Standard 55-2010. "Thermal Environmental Conditions for Human Occupancy.” American Society of Heating, Refrigerating and Air-Conditioning Engineers, Inc. www.ashrae.org.

ASHRAE Fundamentals. 2009. American Society of Heating, Refrigerating and AirConditioning Engineers, Inc. www.ashrae.org.

ASHRAE Standard 90.2. 2007. American Society of Heating, Refrigerating and AirConditioning Engineers, Inc. www.ashrae.org.

ASHRAE Standard 62.2. 2010. American Society of Heating, Refrigerating and AirConditioning Engineers, Inc. www.ashrae.org.

Bankrate Mortgage Calculator. http://www.bankrate.com/calculators/mortgages/mortgagecalculator.aspx

Building America. 2013. http://www1.eere.energy.gov/buildings/residential/ba_index.html

Building Science Corporation. 2009. 65 \% Net Zero Energy Residential Test Facility Construction Documents Set.

Department of Energy, Building Technologies Program, EnergyPlus energy simulation software Version 8.0.0, 2013, http://apps1.eere.energy.gov/buildings/energyplus/.

Energy Information Administration. 2011. Average retail price of electricity to ultimate customers: By end-use sector and utility - residential sector by state and utility - PEPCO. http://www.eia.gov/electricity/data.cfm\#sales

Environmental Protection Agency. 2012 Nissan Leaf EPA Fuel Economy Rating. http://www.fueleconomy.gov/feg/noframes/32154.shtml

Everyday Green, 2012, Building Leakage Test of the Net Zero Energy Residential Facility.

Freddie Mac. U.S. Primary Mortgage Market Survey. July 18, 2013. http://www.freddiemac.com/pmms/.

Google SketchUp 8 software. http://www.sketchup.com/.

Hendron, R., Engebrecht, C., October 2010, Building America house simulation protocols, National Renewable Energy Laboratory, Building Technologies Program.

International Code Council, Inc. 2011. 2012 International Energy Conservation Code - Chapter 4: Residential Energy Efficiency. 
Kneifel, Joshua. September 2012. Annual Whole Building Energy Simulation of the NIST Net Zero Energy Residential Test Facility Design. NIST TN 1767.

National Renewable Energy Laboratory. PVWATTS software. http://www.nrel.gov/rredc/pvwatts/.

Sherman, M.H. and Grimsrud, D.T. 1980. Infiltration- Pressurization Correlation: Simplified Physical Modeling. ASHRAE Transactions, 86(II), 778-807. 